\title{
NEUROPSYCHOPHARMACOLOGY REVIEWS Sex differences and the neurobiology of affective disorders
}

\author{
David R. Rubinow ${ }^{1}$ and Peter J. Schmidt ${ }^{2}$
}

Observations of the disproportionate incidence of depression in women compared with men have long preceded the recent explosion of interest in sex differences. Nonetheless, the source and implications of this epidemiologic sex difference remain unclear, as does the practical significance of the multitude of sex differences that have been reported in brain structure and function. In this article, we attempt to provide a framework for thinking about how sex and reproductive hormones (particularly estradiol as an example) might contribute to affective illness. After briefly reviewing some observed sex differences in depression, we discuss how sex might alter brain function through hormonal effects (both organizational (programmed) and activational (acute)), sex chromosome effects, and the interaction of sex with the environment. We next review sex differences in the brain at the structural, cellular, and network levels. We then focus on how sex and reproductive hormones regulate systems implicated in the pathophysiology of depression, including neuroplasticity, genetic and neural networks, the stress axis, and immune function. Finally, we suggest several models that might explain a sex-dependent differential regulation of affect and susceptibility to affective illness. As a disclaimer, the studies cited in this review are not intended to be comprehensive but rather serve as examples of the multitude of levels at which sex and reproductive hormones regulate brain structure and function. As such and despite our current ignorance regarding both the ontogeny of affective illness and the impact of sex on that ontogeny, sex differences may provide a lens through which we may better view the mechanisms underlying affective regulation and dysfunction.

Neuropsychopharmacology (2019) 44:111-128; https://doi.org/10.1038/s41386-018-0148-z

\section{INTRODUCTION}

Historically, sex differences were largely ignored or were avoided. Investigators would justify the exclusion of females because they were "too complicated," largely as a function of ovarian cyclicity that compromised efforts to achieve a "stable" hormonal environment. The obvious correlate (and paradox) of this objection is that there is something about the female ovarian cycle that must be relevant as an explanation for the inferred variance in outcomes that would be observed were females included in studies. Indeed, as evidence accumulated for the ubiquity and consequential nature of sex differences, the importance of sex as the source of untapped factors for resilience and susceptibility-across the medical spectrum-became clear and led to the decision by the National Institutes of Health $(\mathrm{NIH})$ in 2015 to require examination of sex in $\mathrm{NIH}$-funded studies. With the proliferation of reported sex differences, several categories of sex differences can be identified: sex differences in physiology can converge in producing the same outcome, the same physiologic processes can diverge and result in different outcomes, reported sex differences may be of unclear physiologic consequence [1], and finally, reported sex differences may be artefactual (e.g., a product of post hoc secondary analysis in the wake of negative findings in the primary analysis) [2]. The real complexity, however, as well as the potential explanatory power emerges when one attempts to map a role of sex onto an outcome, in our case, affective regulation. Sex can directly impact etiopathogenesis affecting physiologically relevant outcomes (e.g., synaptic pruning in autism), impact fundamental brain processes (e.g., arousal, reward) or peripheral physiological processes (e.g., immune or hepatic function) that can influence symptom expression or response to treatment (e.g., pharmacokinetics or dynamics), differentially affect response to the environment (e.g., stress exposure), elicit different responses from the environment (e.g., cultural consequences of sex), create differential exposure to hormones (which can alter cellular function and response at the receptor, signal transduction, transcriptional and translational levels), alter cellular metabolism in a sex chromosome-specific, hormone-independent fashion, and program physiologic function - sensitivity and resilience-as a consequence of sex chromosome dosage and prenatal sex steroid exposure. By any standard, this represents a daunting complexity.

In this article, our task-definition of the potential contribution of sex differences to the understanding of affective regulation-is further complicated by both the volume of reported findings and the considerable gaps in our knowledge of the substrates and processes underlying affective regulation. Quite simply, the combined scope of this topic precludes comprehensive review. Consequently, we will provide a framework for thinking about the contributions of sex to affective illness focused on four questions: How would sex alter brain function; Are there sex differences in the brain; Are there sex differences in the substrates of affective regulation; How might sex contribute to differential capacity for affective regulation?

\section{OVERVIEW OF OBSERVED SEX DIFFERENCES IN AFFECTIVE DISORDERS}

The most consistent and robust sex difference reported in affective disorders is the twofold increased lifetime prevalence of major depression (MDD) in women compared with men [3-6].

\footnotetext{
${ }^{1}$ Department of Psychiatry, University of North Carolina, Chapel Hill, NC, USA and ${ }^{2}$ Behavioral Endocrinology Branch, NIMH, Bethesda, MD, USA
}

Correspondence: David R. Rubinow (David_rubinow@med.unc.edu)

Received: 20 March 2018 Revised: 14 May 2018 Accepted: 25 June 2018

Published online: 9 July 2018 
This increased prevalence has been observed in a variety of countries [5]. Similarly, a two- to threefold increased prevalence of dysthymia and threefold increase in seasonal affective disorder [7] as well as increased lifetime risks for other stress-related disorders (e.g., anxiety disorders and posttraumatic stress disorder (PTSD) [8-10]) in women have also been noted. Although the prevalence of bipolar disorder is equi-prevalent in men and women $[3,6,11]$ (reviewed in ref. [12]), women are more likely to develop rapid cycling [12] and may be more susceptible to antidepressantinduced rapid cycling [13]. Interestingly, depression prevalence rates are not observed to be higher in girls prior to mid-puberty/ menarche [14-20], possibly reflecting ascertainment bias/reporting bias (depressed boys may be more likely to come to the attention of health care providers than depressed girls) or the possibility that prepubertal major depression is premonitory of bipolar illness [21] or that alterations in ovarian hormone levels proximate to menarche combine with earlier developmental risks in girls to increase vulnerability [22]. With some exceptions, the age of onset $[4,5,23-26]$ (but also see [27-30]), type of symptoms, severity, and likelihood of chronicity and recurrence $[4,5,26,27$, 31-33] (but also see [34-40]) display few consistent differences between men and women. Clinically, the following are more likely in women: present with anxiety, atypical symptoms, or somatic symptoms [7, 26, 27, 37, 39, 41, 42]; report symptoms, particularly in self-ratings [7, 26, 41]; report antecedent stressful events [43, 44]; and display increased comorbidity of anxiety and eating disorders [30, 45, 46], thyroid disease [47, 48], and migraine headaches [49], as well as lower lifetime prevalence of substance abuse and dependence $[27,30,50]$. Some sex differences in treatment response characteristics have also been observed, with women (compared with men) more frequently reporting a poor response to tricyclics [51-54] particularly in younger women [53] but a superior response to selective serotonin reuptake inhibitors (SSRIs) or monoamine oxidase (MAO) inhibitors. [55-57], with the caveats that reports are not consistent, the sex difference in efficacy may reflect different tolerance of side effects, and several meta-analyses fail to replicate the observed sex difference $[58,59]$. Additionally, anecdotal reports suggest that women derive a greater benefit in their antidepressant response to tricyclic antidepressants from triiodothyronine (T3) augmentation [48, 60]; however, recent controlled trials with T3 augmentation of SSRIs have found neither beneficial overall therapeutic effects nor sex differences in response characteristics [61-64]. The extent to which some differences in response reflect sexrelated differences in pharmacokinetics [65-71] remains to be determined. In general, although differences in pharmacokinetics have been observed as a reflection of differences in absorption (gastric acidity and transit time), volume of distribution, and metabolism (sex differences in CYP 1A2, 2D6, and 3A4) [58, 72], these differences do not materially influence the dosing of or response to antidepressants. In fact, the hypnotic zolpidem is the only psychopharmacologic agent for which different dosing is recommended on the basis of sex [73]. Finally, some women will experience significant mood disorders during periods of reproductive hormone change including during the luteal phase of the menstrual cycle, puerperium, and the perimenopause, which have no analogs in men. The contribution of these sex-specific disorders to the increased prevalence of depression in women is unclear.

The sex differences in both epidemiologic and clinical observations are increasingly complemented by demonstrations of sex differences in a wide range of genetic and neurobiological measures relevant to affective disorders in humans. It is to these "etiopathogenic" sex differences that we now turn in an attempt to answer the following question: in the absence of extensive or actionable sex differences in affective disorder, why would one think that sex differences are critical to our understanding of affective regulation and dysregulation.

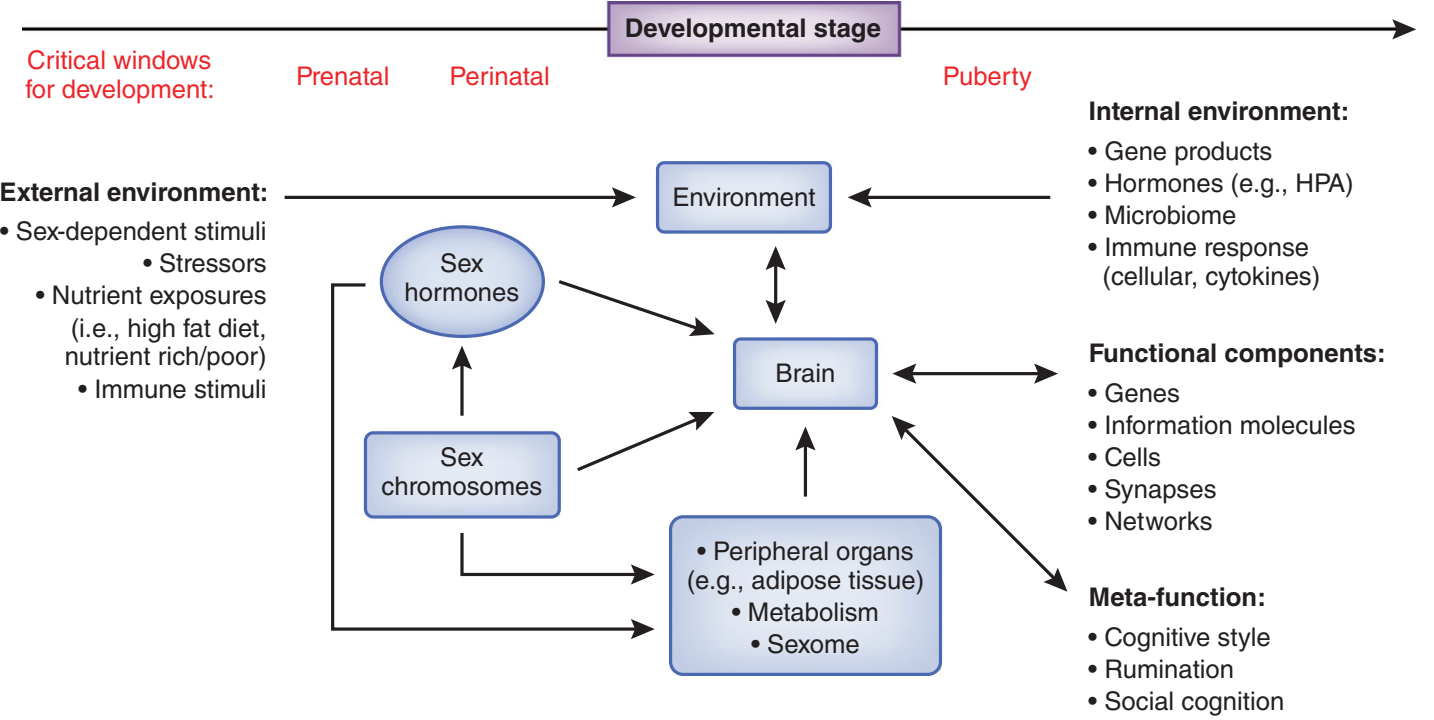

Fig. 1 Schematic depiction of the multiple levels at which sex influences brain function. Sex is a ubiquitous, context-creating modulator of brain and behavior, accomplished through both organizational effects that program subsequent brain sensitivities and development, and activational effects that acutely impact neural function. Sex influences the internal environment in which brain function occurs (e.g., differential exposure to stress or immune soluble molecules) as well as modulating the impact of the external environment (e.g., diet or stressors, particularly in the prenatal environment, or even social responses from others based on sex). Sex chromosomes impact brain development directly, may impact physiology through differences in exposure to gene products (e.g., sex-linked genes or differences in gene dosage), and alter brain function developmentally and activationally through sex-determined gonadal function and differential exposure to sex hormones. Sex differences in peripheral organs (e.g., adipose, liver) lead to differential exposure of the brain to hormones as well as medications (through effects on metabolism). The sexome refers to the cumulative array of sex-related modulatory effects on intracellular molecular interactions. Sex differences appear at all levels of neural organization, from cell to circuit. Finally, reported sex differences in metacognitions may influence perception and processing of environmental stimuli, thus influencing affective generation and regulation (references appear in the text) 


\section{HOW WOULD SEX ALTER BRAIN FUNCTION (THE LOCUS OF AFFECTIVE REGULATION)?}

The data required to answer this question fall into three main categories: hormonal effects, which include acute or activational effects and programming or organizational effects; effects of genomic sex (i.e., effects independent of hormones but dependent on the presence of $X$ vs. Y chromosomes); and environmental effects (which include effects on an organism consequent to being one sex or the other, "downstream" effects of peripheral sex differences (e.g., differences in metabolism), and sex differences shaped by interactions with the environment (e.g., stressors)). While these effects are discussed separately below, it is increasingly clear that many sex differences represent the composite or integrated effects of genetics, environmental, and sex steroid exposures (see Fig. 1). (Of note, throughout this paper we use "sex" to refer to biological sex as contrasted with "gender," which refers to sexual identify or social role and may be associated with specific environmental challenges.)

\section{Hormonal effects}

Programming/organizational effects. Reproductive hormones quite literally shape brain architecture as well as subsequent sensitivities. The classical studies of Phoenix, Gorski, and Arnold [74-76] established that exposure of the brain to reproductive steroids during critical periods of development influenced the development of behavioral capacities (e.g., aggression, sex behaviors) and further "programmed" the brain so as to elicit a different behavioral response in adulthood upon re-exposure to reproductive steroids. Exposure of the perinatal rodent to testosterone increases local exposure to estradiol (E2) (an aromatized metabolite), which is responsible for masculinizing the brain and permitting subsequent "male" behaviors. These programmed capacities were complemented by observations of sex differences in brain morphology and synaptic organization [77, 78].

During critical periods of brain development (i.e., in utero and, in humans, possibly puberty) sex steroids have the capacity to regulate many if not all of the processes (and signaling molecules) involved in the regulation of functional brain development, including neuroplasticity and epigenesis, as well as immune factors (e.g., microglia) relevant to sex-specific brain development. For example, in the Syrian hamster, sex steroids secreted during puberty regulate levels of spinophilin, synaptophysin, glyceraldehyde 3-phosphate dehydrogenase (GAPDH), and synaptic pruning of the medial amygdala and thereby influence social and mating behaviors [79]. In rodents, during embryonic and early postnatal development, estradiol and testosterone permanently masculinize several behaviorally relevant brain structures (e.g., bed nucleus of the stria terminalis (BNST) and medial preoptic area (POA)) through modulation of the enzymes regulating epigenesis (e.g., DNA methyltransferase) $[80,81]$. Indeed, masculinization of both the POA and BNST (and its behavioral consequences) can be prevented by administering histone deacetylase (HDAC) inhibitors [81-83]. Finally, in neonatal rats E2 regulates microglial number and morphology/activation in the preoptic area, which in turn regulate the process of masculinization and subsequent related behaviors [84]. These programmed differences in brain structure and function in animals potentially manifest at multiple levels of physiologic function from genetic to cellular to circuit level and have provided a major source of inference about the role of gonadal steroids in human brain function and behavior.

Acute/activational effects. There is virtually no element of neural function that is not regulated by reproductive hormones. This is unsurprising for several reasons: (1) reproductive steroid receptors are among the oldest signaling molecules (e.g., the E2 receptor existed for millions of years prior to the appearance of E2 in the steroid metabolic cascade) [85], a fact that helps to explain why, as intracytoplasmic molecules, reproductive steroid receptors act as a point of convergence of multiple intracellular signaling pathways; and (2) without the ability to coordinate reproductive motivated behavior and biology, species do not last long. Teleology aside, from cell to circuit, neural activity is modulated by reproductive steroids.

Neural structure. In addition to programmed modification of neural structure, reproductive steroids can acutely modify neural wiring/connectivity [86, 87]. For example, E2 acts through membrane-initiated signaling involving metabotropic glutamate receptor 1 (mGLUR1) to phosphorylate and deactivate cofilin, an actin severing protein. The resulting change in the cellular cytoskeleton produces acute (within $30 \mathrm{~min}$ ) appearance of new synaptic spines, which will become permanent if followed by activity-dependent depolarization [86, 88, 89]. As such, E2 can influence both acute and sustained synaptic wiring.

Neural excitability. For at least 30 years, it has been known that reproductive steroids and their metabolites (e.g., the progesterone metabolite allopregnanolone) are able to acutely-within minutes —and more chronically modulate neural excitability [90-92]. The mechanisms involved in the acute, membrane-initiated signaling include direct binding of ion channels and of ligand gated ion channels, activation of G-protein-coupled receptors (leading to Gprotein regulation of ion channels), and second messengermediated modulation of membrane conductance [88, 93, 94]. E2 directly binds and potentiates L-type voltage gated calcium channels [95], acts through estrogen receptor-beta (ER- $\beta$ ) to increase calcium-activated potassium currents (through BK (Big Potassium) potassium channels) to rescue neuronal excitability after $\mathrm{O}_{2}$ /glucose deprivation [96], and directly binds and activates Slack potassium channels [97]. In addition to binding ion channels and receptors to alter conductance, E2 can alter genes that determine membrane properties underlying intrinsic excitability. With long-term E2 deprivation, CA1 neurons show decreased intrinsic excitability, less efficient generation of stimulated action potentials and long-term potentiation (LTP), and loss of sensitivity to the acute immediate/early regulatory effects of E2 [98].

Regulation of neural cell function. Reproductive hormones regulate virtually all elements of neuronal (and glial) function, including intracellular signaling, transcription, epigenetic modification of transcription, and (protein) translation. Hormonal regulation of the membrane concentrations of canonical neurotransmitters influences the extent and balance/nature of cell signaling. In turn, through both genomic and nongenomic effects, reproductive steroids like E2 regulate signal transduction through direct effects on $\mathrm{Ca} 2+/$ calmodulin-dependent protein kinase II (CaMKII; calcium), protein kinase A (PKA; cyclic adenosine monophosphate (cAMP)), extracellular signal-regulated kinase (ERK; mitogens, growth factors), phosphatidylinositol-3-kinase (PI3K)/Akt (growth factors, insulin), and G proteins (cAMP, calcium, $\mathrm{PI} 3$, etc) [93, 99-102]. Not surprisingly, the effect seen depends on the cellular context (e.g., mitogen-activated protein kinase (MAPK) is increased by E2 in neurons and decreased in glia) [103, 104]. E2, through its receptor, regulates gene expression through DNA estrogen response elements (ERE) as well as by tethering to activator protein-1 (AP1), specificity protein-1 (SP1), and nuclear factor (NF)-KB, permitting the regulation of genes without EREs [105]. At the level of transcription, E2 regulates all three RNA polymerases, thus influencing general transcription as well as the production of micro-RNAs, ribosomal RNA, and even transfer RNAs [106]. Indeed, up to one-third of the 500 or so transfer RNAs are robustly and rapidly upregulated by short-term exposure to E2 [106]. Via these means, E2 regulates not only short-term transcription but also potently upregulates the entire protein biosynthetic apparatus. The epigenetic machinery by which 
environmental events alter transcription is influenced at multiple levels by E2; i.e., regulation of histone acetylation (through effects on both histone acetyltransferase and histone deacetylase) and methylation (through DNMT3b [107, 108]). These effects are at least in part mediated through rapid signaling effects of E2 (e.g., ERK, PI3K), leading, for example, to increased histone acetyltransferase activity and acetylation of $\mathrm{H} 3$ (not $\mathrm{H} 4$ ) and target genes, decreased HDAC2 (but not HDAC3) levels, and increased DNMT3b (but not DNMT1) [109]. These effects in hippocampus mediate long-term memory formation.

Regulation of neural transmission. Evidence from animal studies and some human studies document the widespread actions of sex steroids (and their metabolites) on neurotransmission, including effects on the glutamate, GABA, serotonin, dopamine, cholinergic and noradrenergic systems, as well as on the function of several important neuropeptides (e.g., brain-derived neurotrophic factor (BDNF), oxytocin) (see refs. [86, 92, 110-115]). The actions of sex steroids impact multiple aspects of neurotransmitter physiology. For example, E2 (and progesterone) regulate multiple aspects of dopaminergic function, affecting the synthesis, release, and metabolism of dopamine [116-118] and modulating dopamine receptor expression and function [92, 110, 119, 120]. However, in keeping with the complexities and diversity of dopamine's neuroregulatory profile, the effects of E2 on dopaminergic function vary in a brain region-specific manner. In rodents, E2 increases stimulated dopamine release in the dorsolateral striatum but inhibits dopaminergic activity in the nucleus accumbens, as well as alters dopamine receptor density and striatal dopamine uptake sites, whereas ovariectomy reduces striatal dopamine receptor density, extracellular dopamine levels, and behaviors mediated by the striatal dopaminergic system [110, 115, 121]. Thus, even within the reward network, E2 can differentially alter the balance between dopaminergic tracts (i.e., striatum vs. accumbens) [122] in female mice. In contrast, it is well established that E2 exerts anti-dopaminergic effects on the anterior pituitary and hypothalamus, where it inhibits dopamine synthesis and prolactin cell responsiveness to dopamine [123]. By modulating dopamine function in the striatum, nucleus accumbens, and prefrontal cortex (PFC), sex steroids may impact both reward and working memory network function. Similar data support the potentially important roles of sex steroids in central glutaminergic and serotonergic system functions, both of which are relevant for affective disorders in women [124-126]. Further, the neurosteroid metabolites of progesterone (allopregnanolone) and testosterone (androsterone) are high-affinity, allosteric modulators of the GABA receptor complex at physiologic concentrations [127]. Most important, the widespread nature of sex steroid regulation of central neurotransmission suggests the capacity for these steroids to modulate the cross-talk among different receptor systems in the complex regulation of behavior.

In women, positron-emission tomography (PET) imaging has been employed to evaluate the effects of ovarian steroids on serotonergic and dopaminergic neurotransmitter system function. Many of these findings parallel observations in animal studies and demonstrate in humans the potential for ovarian steroids to regulate these neurotransmitter systems. Studies have employed a range of PET ligands (MAO-A binding $\left({ }^{11} \mathrm{C}\right.$ harmine), serotonin transporter binding $\left({ }^{11} \mathrm{C}\right.$ DASB, ${ }^{11} \mathrm{C}$ MADAM), serotonin $2 \mathrm{~A}$ receptor binding (18F deuteroaltanserin), dopamine receptor binding $\left({ }^{11} \mathrm{C}\right.$ raclopride) $)$ across several different hormonal conditions in healthy women (i.e., postpartum, across the menstrual cycle, pre- and post-hormonal therapy, or in the context of gonadotropin-releasing hormone (GnRH) agonistinduced ovarian suppression). Overall, findings show an effect of hormonal state on most of these measures (although no menstrual cycle-related differences were observed in ${ }^{11} \mathrm{C}$ raclopride binding [128]). With the exception of two studies using different serotonin transporter ligands, both showing that estrogen decreased binding [129, 130], and one showing an increase in serotonin $2 \mathrm{~A}$ receptor binding after estradiol therapy [131], the direction of the effects related to either high or low levels of ovarian steroids are inconsistent across studies and could reflect differences in study conditions and the age of the women studied [132-134].

Circuit regulation. Reproductive hormone-dependent changes in cell function lead to both structural and functional changes in neural circuitry. Srivastava et al. [99] observed that E2 may rapidly alter neuronal "wiring" by increasing synaptic spines, which become permanent if followed by activity-dependent depolarization [89]. As mentioned above, rapid E2-stimulated membraneinitiated signaling increases immediate/early gene transcription (in a methylation-dependent and, hence, epigenetic fashion), acts through mGLUR1 to induce dendritic remodeling, and alters AMPA receptor trafficking and LTP, thus modifying both neuronal morphology/structure and connectivity [86].

In humans, neuroimaging studies have employed a range of experimental conditions (e.g., across the menstrual cycle, during ovarian steroid hormone manipulation protocols, and before and after ovarian steroid replacement in menopausal women) to examine neural targets of ovarian steroids in women. Both PET and functional magnetic resonance imaging (fMRI) measures have been employed with a variety of paradigms to examine specific neural systems. Neuroregulatory effects of both E2 and progesterone have been documented in working memory (dorsolateral prefrontal cortex (DLPFC), hippocampus) [135-137], reward (orbitofrontal cortex (OFC), amygdala, striatum) [138-141], default mode (medial prefrontal cortex (mPFC), rostral anterior cingulate) [142-144] (although also see refs. [145-147]), emotional processing (amygdala, OFC, anterior cingulate cortex (ACC)) [148-153], and hubs within the salience network (insula) $[149,154,155]$. Thus, ovarian steroids have the potential to modulate many of the functional brain networks underlying alterations in affective state [156-162].

\section{Sex chromosome effects}

In an elegant experiment in mice, De Vries et al. [163] (also see ref. [164]) created a four-core genotype in which Sry-the gene that codes for the factor that results in the development of testeswas transferred to an autosome, thereby permitting assessment of the effects of sex chromosomes independent of gonadal/ hormonal effects. They clearly demonstrated the complexity of sex chromosome and sex steroid influences on brain development and that several sex differences in physiology and behavior were determined in a sex chromosome/hormone-independent fashion. For example, in addition to directing the development of the testes and testosterone exposure, the presence of the Sry gene can influence neuronal response to stress well before there is any evidence of testes development or the secretion of testosterone [165]. Indeed, both $X$ and $Y$ chromosomes contain multiple genes relevant to brain development [166-169]. With the exception of genes shared by $X$ and $Y$ chromosomes, males contain genes only from one $X$ chromosome (from the mother), whereas females have one maternal copy and one paternal copy of each X-related gene, either one of which could convey disease risk or resilience. To maintain homeostasis in overall X-gene expression, the dosage of X-linked genes is balanced by the epigenetic silencing of one copy of the female $X$ chromosome (i.e., $X$ inactivation of parent-oforigin genes-either the maternal or paternal). It is believed that this process results in an equal selection for maternal vs. paternal $X$ silencing, although the origin of the silenced $X$ may vary in $a$ tissue-specific manner and can change with aging [170-174]. Further complexity has been identified in women, in whom a relatively large number of $X$-linked genes (up to 15\%) escape silencing (including those $X-Y$ paired genes thought to share 
similar functional properties), and consequently gene dosage effects can arise in women whereby a larger proportion of $\mathrm{X}$ related genes are expressed [175-177]. The potential relevance of genes escaping $X$ inactivation to disease processes in women has recently been defined in $T$ and $B$ lymphocytes from women who show bi-allelic gene expression (i.e., expression of genes from both $\mathrm{X}$ chromosomes) in several immune-related genes that could contribute to the increased prevalence of autoimmune diseases (i.e., Lupus) in women [178]. Thus, the expression of Xchromosome genes in women can be influenced by individual differences in the parent-of-origin genes being expressed (i.e., imprinting), $X$ inactivation (and the escape of $X$ inactivationincluding skewing of the proportions of paternal or maternal alleles present within cells [179]), and, possibly, the impact of interactions between the inactivated $\mathrm{X}$ chromosome and other autosomes [180-182].

Sex chromosome effects in non-brain tissues can also potentially contribute to altered brain development and sex-specific disease risk. For example, in gonadectomized mice in the fourcore genotype experimental manipulation, XX mice-regardless of the type of gonad present-had greater food intake (and adiposity) during daylight hours and exhibited a greater risk for a metabolic syndrome-like phenotype [183-185]. These effects represented abnormal $X$ gene dosage due to the escape of several $X$ genes from inactivation and could impact both circulating sex steroid levels (due to the presence of steroid synthetic enzymes in adipose tissue) and inflammatory processes, either of which influence brain function. The potential widespread physiologic impact of different sex chromosomes and gene dosage is underscored by observations that genes function in networks, and alterations in the expression of even a single gene may alter the function of that network. It is not surprising, therefore, that sex differences in transcriptional profiles vary by tissue and are as high as $72 \%$ in liver, $68 \%$ in adipose tissue, $55 \%$ in muscle, and $14 \%$ in brain [186]. Finally, mitochondrial genes are only transmitted from the mother, and, therefore, natural selection can act only through women to optimize mitochondrial gene function [187]. The corollary of this process is that the function of mitochondrial genes may not be optimized in men and, therefore, potentially conveys disease risk in men. Moreover, studies suggest that some mitochondrial DNA contains functional EREs, and since ER- $\beta$ can be imported into mitochondria, it is possible that sex steroids can also regulate mitochondrial gene function $[188,189]$.

\section{Environmental effects}

It is axiomatic that the environment shapes the brain, and there are a multitude of ways in which sex interacts with the environment in this process. First, women are subject to very different environmental responses than men, with many of the resultant effects consequent for brain development. Sex-related traumatic sequelae, for example, are enduring and profound, altering (at the least) cognitive, behavioral, and physiological response to subsequent stressors. Second, environmental stimuli (e.g., stressors) may be processed in a sex-dependent fashion (see below). Third, sex-related differences in peripheral organs (e.g., hepatic function) can expose the brain to a different "environment" [190]. Fourth, the maternal-placental-fetal unit contributes to fetal development in several ways, including populating serotonin neuronal concentrations in the mouse and human fetal brain [191]. Finally, sex may select a different environment that affects subsequent risk, as seen by Markle et al. [192] in the study of the role of the microbiome in risk for diabetes. These investigators were able to eliminate the overwhelming sex difference in the risk of diabetes in a strain of mice (non-obese diabetic (NOD)) - four times higher in females-by transplantation of gut contents from an adult male to the young female. This remarkable effect was dependent on a sustained increase in testosterone induced in the females by the transplanted microbiota.

\section{ARE THERE SEX DIFFERENCES IN THE BRAIN?}

Structure

Despite the presence of several well-documented sex differences in brain morphology, innervation, and regional composition in animals [193], many of which may not be observed within the same order (e.g., rats vs. mice [194]), only a few robust sex differences in humans have been demonstrated consistently. First, women with Turner syndrome (with only a single X chromosome) have smaller MRI-measured volumes of several brain regions, including the hippocampus, caudate, and parieto-occipital cortex, suggesting the role of X-chromosome imprinting or Xchromosome dosage on gray matter morphology [195]. Sex differences in gray matter (GM) volume have also been observed in normal men and women, with women observed to have a higher percentage of GM volume (relative to white matter) and cerebrospinal fluid, despite controlling for total intracranial volume [196, 197], and greater volumes of the orbital frontal cortices, but not hippocampus, amygdala, or DLPFC [198] (although see ref. [199] in which increased hippocampal volume is observed in girls compared with boys after puberty). In contrast, a recent meta-analysis reported that men had higher gray matter densities than women in several brain regions, including amygdala, hippocampus, insular cortex, and putamen [200]. Indeed, a postmortem study found that men have higher cortical synaptic density in all layers of the temporal neocortex [201]. Sex differences in the effects of aging on cortical volumes [202] and inter- and intra-hemispheric connectivity (as described below) have also been reported [203, 204]. Many of these sex differences emerge during adolescence, and some studies suggest a critical regulatory role of androgens and the androgen receptor in the developmental trajectories of these differences [205-210]. Thus, both the X-chromosome and sex steroid exposures across the lifespan potentially can alter structural volumes in men and women. A more recent analysis of 1400 adults in which male and female patterns of GM, white matter, and connectivity were defined a priori on the basis of a separate cohort of scans demonstrated a substantial overlap in sex-specific patterns in all brain regions examined. Although the analytic methods employed are controversial and the cohort was assembled from several studies employing differing methodologies (see refs. [211-216]), these data suggest that in humans individual differences contribute more variance to brain structure and connectivity than does sex [217]. Several caveats deserve mention. It is likely that the impact of structural sex differences on affective regulation is brain region specific, and, therefore, overall gray and white matter volumes might be less relevant. Moreover, the methods employed to measure regional volumes vary considerably across studies (see above). Thus, in contrast to the animal literature, inconsistencies in structural brain assessments at the human level probably reflect a range of methodologic complexities and signal the need for additional research to resolve these issues and identify meaningful and generalizable findings.

Cell activity/signaling differences. The functional end of sex effects in the brain is the cell (neuron, glia). Multiple sex differences in cellular signaling have been observed and attributed to both sex-related programming and acute hormonal effects. For example, Huang and Woolley [218] showed that although E2 acutely potentiated excitatory postsynaptic potentials equally in males and females, E2-suppressed, rapid, perisomatic synaptic inhibitory transmission occurred only in females. This E2 suppression of inhibition (in oophorectomized females) was mediated through ER-a, mGluR1, and endocannabinoid signaling, and Tabatadze et al. [219] observed sex differences in both E2- 
dependent and E2-independent regulation of the hippocampal endocannabinoid system. They demonstrated that ER-a/mGluR1/ IP3R signaling is regulated by E2 only in females-despite comparable levels of ER-a, mGluR1, IP3R-and E2-independent hippocampal tonic endocannabinoid release exists in female (but not male) rats. These findings of presumed programmed sensitivity parallel those of Boulware et al. [220] and Meitzen et al. [221] showing that rapid, E2-stimulated CREB phosphorylation, which occurs only in females, can be eliminated by postnatal exposure to E2 or testosterone (and hence, again, is an organized sensitivity). Although the mechanisms underlying these postreceptor differences in ER-a signaling are unknown, Oberlander and Woolley have identified a striking sex difference in the role of ERs in E2 regulation of glutamate signaling in the hippocampus: glutamatergic presynaptic signaling is mediated by ER-a in males and ER- $\beta$ in females, while postsynaptic signaling is mediated by ER- $\beta$ in males and GPR30 in females [222]. Another organized sex difference (i.e., unaffected by varying hormonal levels) in signaling is that of corticotropin-releasing factor (CRF)-mediated signaling in the locus coeruleus [223]. There, the differential coupling of CRF receptor 1 to $\beta$-arrestin-2 (more in males) favors Gs-mediated pathways (PKA, ERK) in females vs. Gs-independent pathways (Rho, Src, ERK) in males [224]. This has striking implications for the processing of stress-related signals as described below. In addition to organized sex-dependent sensitivities, many sex differences in neural signaling reflect differential exposure to acute, regulatory effects of reproductive steroids. These include E2-stimulated BDNF transcription (with corresponding increased expression in females compared with males during the high E2 phase of the estrus cycle), phosphorylated (activated) axonal Trk-B (the receptor for BDNF), and associated synaptic plasticity [225]. Particularly noteworthy is the demonstration that many observed sex differences in gene expression (and that link to sex-typical behaviors) depend on adult exposure to testosterone in males but are independent of adult ovarian hormones in females [193].

Network differences. The existence of sex- and hormone-related effects on brain region structural connectivity and activation provide a basis for inferring differential network processing between sexes. Multiple sex differences in the rat basolateral amygdala were recently described, including increased neuronal firing rates, more dendritic spines, and greater sensitivity/responsivity to glutamate (via iontophoresis) in females [226]. Further, both organized and activated sex differences in dendritic structure in the locus coeruleus and hippocampus provide examples of "wiring" differences and synaptic remodeling that are associated with differential circuit function $[112,224]$. Suggestions of sex-related differential cortical dynamics in humans are primarily derived from three sources: neurocognitive studies showing better female performance on memory and social cognition tasks vs. better male performance on spatial and motor speed tasks (but see refs. [227-229]; electroencephalography (EEG) studies demonstrating greater laterality in male brains [230]; and diffusion MRI tractography studies [204] (but also see ref. [231]). MRI studies with graph theoretical analysis of anatomical connectivity suggest that, despite overlap, women show significantly higher overall connectivity as well as increased local and global efficiency (after controlling for brain size) [232]. Ingalhalikar et al. [204] demonstrated prominent sex differences in cortical connectivity patterns, whereby men showed greater withinhemispheric connectivity (favoring coordination of perception and action), whereas female brains have greater between-hemispheric connectivity, facilitating "communication between analytical and intuitive processing modes." Sex differences in connectivity patterns (both functional and structural) were also observed by Tunc et al. [233] and Satterthwaite et al. [234] (but see ref. [235]). Nonetheless, in a large MRI study, Joel et al. [217] concluded that although sex differences in brain and behavior are observed, the overlap in all brain regions between men and women is extensive, and the internal consistency within even a single brain is far less common than variability; i.e., individuals are mosaics, with volume or connectivity of brain regions (and behaviors) spanning the male/ female continuum in a region (and behavior)-specific fashion.

\section{ARE THERE SEX DIFFERENCES IN THE SUBSTRATES OF AFFECT REGULATION?}

Many physiologic systems and processes have been implicated as contributing to the etiopathogenesis of depression. These include neurotransmission, neuroplasticity, stress axis, immune function, and neural and genetic network regulation. As described below, sex-related differences as well as reproductive steroid-related modulation have been observed in each of these processes. (The existence of reproductive steroid regulatory effects provides a basis for inferring sex-dependent differential function of these systems, but, as noted above, differences at the molecular level may converge to result in similar physiologic endpoints.) Several examples follow, with greater attention paid to dysregulation of immune function, stress reactivity, and neural network function.

\section{Neurotransmission}

As described above, the effects of reproductive steroids on neurotransmission are profound, affecting all levels of function including neurotransmitter synthesis and metabolism, receptor synthesis and trafficking, and signal transduction. Not surprisingly, therefore, there are many reported sex differences, many of which are brain region specific, in the concentrations, receptors, and metabolites of classical neurotransmitters as well as in their elicited intracellular signals and cellular actions. These are reviewed elsewhere (see refs. [86, 92, 110, 111, 114, 115]).

Neuroplasticity. Alterations in neuroplasticity, including neurogenesis, cell death, and synaptic remodeling, are some of the fundamental processes that underlie the development of sex differences in the brain [194]. Sex steroids differentially regulate many of the molecules involved in neuroplasticity (e.g., neurotrophin secretion), as well as several of the physiologic systems (e.g., glutamatergic and GABA-ergic) $[112,236]$ regulating the opening and closing of critical developmental windows [237]. Thus, exposures to sex steroids could regulate sex-specific "opportunities" for the effects of physiologic events (e.g., puberty) or adversity to differentially impact developmental (re)programming and the instantiation of behavioral risk over the life cycle. Sex differences in the mechanisms of neuroplasticity have been reported, particularly in the hippocampus, a brain region implicated in affective dysregulation [238]. In knock-out mice, calcium/calmodulin kinase kinases appear to play a more significant role in hippocampal neuroplasticity in males compared to females [239], whereas females but not males show synapse induction within the hippocampus by E2 (although testosterone will induce synapse formation in males (in vivo) [240]). Similarly, the pattern of hippocampal synaptic remodeling of CA3 dendrites after chronic stress exposure is observed in males but not females [241] (reviewed in ref. [113]). The relevance of these differences in hippocampal neuroplasticity to sex differences in human brain function (or disease) remains to be clarified. Additionally, several sex differences in neuroplasticity after administration of ketamine (an N-methyl-D-aspartate (NMDA) receptor antagonist used for treating depression [242]) have been reported in socially isolated rodents [243]. For example, ketamine reversed the decreased spine density in the medial prefrontal cortex in males but not females [244]. These differences also likely reflect differences in the impact of social isolation on male and female mice $[245,246]$. Recently, female mice were observed to have threefold increased levels of hydroxynorketamine, the ketamine metabolite with rapid antidepressant-like actions, in the absence of NMDA receptor inhibition [247]. Thus, although a recent report from human 
studies did not identify sex differences in the antidepressant effects of ketamine in treatment-resistant depression [248], it is possible that sex differences in the sensitivity to ketamine could emerge in larger samples.

There is considerable evidence that reproductive steroids modulate neuroplastic processes implicated in depression and/ or the antidepressant response. E2, for example, does the following: acts like antidepressants (and opposite to stress) in stimulating BDNF [249]; increases activity of the transcription factor CAMP response element-binding protein (CREB) [250] and trkA (neurotrophic tyrosine kinase receptor type 1) [251,252]; and decreases glycogen synthase kinase- $3 \beta$ in rat brain [253], the same direction of effects as seen with mood stabilizers. Interestingly, sex differences are observed in the facilitative effects of E2 on neuroplasticity. Although the effect on synaptic activity (i.e., potentiation of glutamatergic synapses in CA1 hippocampal slices) is similar, the mechanism involves ER- $\beta$ (and possibly GPER1) in females vs. ER-a in males [222].

Neuroprotective effects of E2 and progesterone (or its neurosteroid metabolites) have also been described in neurons grown in serum-free media or those exposed to glutamate, amyloid- $\beta$, hydrogen peroxide, ischemia, or glucose deprivation [254-258] (see also ref. [259]). Some of these effects appear to lack stereospecificity (i.e., are not classical steroid-receptor mediated) and may be attributable to the antioxidant properties of E2 or the $\mathrm{GABA}_{\mathrm{A}}$-modulating effects of allopregnanolone, although more recent data support steroid receptor-mediated mechanisms of action. Gonadal steroids may also modulate cell survival through effects on cell survival proteins (e.g., $\mathrm{Bcl}-2, \mathrm{BAX}$ ), signaling pathways (e.g., MAPK, Akt), intracellular calcium regulation, metabolism of amyloid precursor protein and $A \beta$, or through enhancing mitochondrial respiratory efficiency [259-262]. Through increased oxidative capacity and efficiency of neuronal mitochondria, E2 promotes neuronal bioenergetics and protects neurons against multiple toxins, including free radicals, excitotoxins, $A \beta$, and ischemia [260]. Damage from oxidative stress to mitochondria promotes apoptosis and cell death, and both estrogen receptor-dependent and -independent neuroprotection at the level of the mitochondria have been described. For example, E2 bound to ER- $\beta$ can be transported into the mitochondria, where it binds an ERE in mitochondrial DNA [188, $189,263]$ and produces a range of anti-apoptotic proteins that maintain the integrity of the mitochondrial membranes. Thus, in addition to its other neurotrophic actions [263], E2 could improve mitochondrial respiratory efficiency by directly inducing transcriptional activity in mitochondrial DNA and prevent the oxygen free radicals that are believed to adversely affect mitochondrial energetics in depression.

\section{Neural and gene network function}

Gene networks: A study of gene co-expression networks showed marked differences between patients with MDD and controls, but strikingly there was little overlap in the altered transcriptional network connectivity patterns in males and females with depression or in mice subjected to chronic variable stress [264]. Of note in this study, a hub gene-Dusp6-was downregulated in a sex-specific fashion in both depressed women and stressed mice, regulated cell signaling and ventromedial PFC pyramidal cell excitation (only in females), and, when downregulated, increased behavioral sensitivity to stressors; i.e., identical manipulations of the same gene led to major differences in both the physiological and behavioral effects in males and females. The sex-specific transcriptional signatures in depression were recently replicated by Seney et al. [265], who observed that of the 700 to almost 900 genes differentially expressed in cortico-limbic regions in men and women with MDD compared with controls, only 73 genes were differentially expressed in both men and women, and 52 of these changed in the opposite direction. Additionally, postmortem studies of men and women with MDD have reported a sex difference in the expression within the dorsolateral prefrontal cortex of multiple glutamatergic genes, with increased expression in women [266]. Finally, several clock genes have been reported to differ in a sex-specific manner, possibly in keeping with reports that women have an overall phase advance in several measures of circadian rhythmicity compared with men [267-269].

Neural networks: Disturbances of amygdalar activity or connectivity have been implicated in affective disorders [270], and sex differences have been described in amygdala activation patterns [271] and connectivity [272]. Of note, the amygdala is differentially activated in men and women as a function of the valence or nature of the affective stimulus, positive or sexual in men and negative in women [273].

Sex differences have been observed in resting state functional connectivity, with several studies finding increased connectivity within statistically defined modules or sensorimotor resting networks (i.e., increased intra-network/module connectivity) in women and increased inter-network or cross-module connectivity in men [234, 274], with the caveat that studies also have reported increased intra- and cross-modular connectivity in girls compared to boys (Reding et al., unpublished observations) as well as other sex-specific patterns of connectivity in boys and girls [275-277]. As emphasized by Mak et al. [277], the divergence in some of these functional connectivity findings reflect differing analytic methods (e.g., independent component analyses vs. seed-based vs. datadriven analyses), potential presence of negative affective symptoms on the day of scanning, and differing ages of participants (e.g., prepuberty vs. adults). Nonetheless, abnormalities in resting state functional connectivity within the default mode network (DMN) have been observed in depressed men and women [157, $158,278]$. However, few if any studies report sex differences in DMN functional connectivity in depression. Recent studies do suggest an association between depressive rumination and functional connectivity between the DMN and the subgenual prefrontal cortex (sgPFC) [157]. Since studies also suggest that women experience a greater amount of rumination during depression than men [279], one could imagine that a sex difference specifically in DMN functional connectivity with the sgPFC may be detected. Alternatively, if confirmed, the presence of sex differences in DMN network activity in asymptomatic men and women, and the absence of comparable differences in depression, could inform our understanding of depressive illness.

A sex difference has been reported in an emotional/arousal network, with men showing greater activation (fMRI bloodoxygen-level dependent (BOLD)) of the anterior cingulate gyrus, OFC, hippocampus, and mPFC when watching negatively valenced/high arousal pictures compared with women during mid-cycle of the menstrual cycle [271]. Using a similar paradigm, these investigators previously also demonstrated that activation patterns in many of these brain regions in women decreased during mid-cycle compared with the early follicular phase, suggesting that higher estradiol levels at mid-cycle attenuated the activity of this network [148]. Thus, sex differences in network level function may also reflect the regulatory effects of sex steroids. This observation is lent further support by the recent discovery of an estradiol-regulated reward circuit in mice [280], again suggesting the contribution of activational effects of sex steroids to differential network function in depression.

Immune function. Multiple lines of evidence suggest that immune dysfunction contributes to the risk for depression. Raison and Miller [281] have proposed the pathogen:host defense model, which suggests that immune activation and stress perception have "co-evolved" to generate sickness behavior (protective in intent) in response to environmental threats and challenges. Additionally, multiple studies identify elevated immune activation 
markers and cytokine levels (e.g., C-reactive protein, interleukin (IL)-6, IL-1B, and tumor necrosis factor-a (TNF-a)) in patients with major depression compared with controls [282, 283]. Multiple sex differences have been described for immune function, stress response (see below), and the interaction of stress and immune function in depression.

Sex differences in immune function or effects include the following. (1) In response to immune activation, females experience more adverse behavioral effects, including increased immobility on the forced swim test and decreased sucrose preference in rodents [284-286] and increased depression and social disconnection in women $[287,288]$. (2) In the immune response itself, in humans some immune cells increased equally in males and females after stress, some to a greater extent in males, some more in females regardless of menstrual cycle phase, and some only in females on oral contraceptives, findings again consistent with both programming and activational sources of sex differences [289]. Further, although lipopolysaccharide-stimulated microglial IL-1B expression in vitro is increased in neonatal males compared with females, it is suppressed by E2 in males and increased by E2 in females, suggesting that not only is the sex difference hormonally responsive, but the effect of the same hormone is opposite in males and females [290]. (3) Sex differences exist in the susceptibility to neuroimmune-related disorders. Autoimmune disorders (including multiple sclerosis (MS), lupus, rheumatoid arthritis, and thyroid disease) show a dramatically increased prevalence (2-9-fold) in women [291], consistent with the increased susceptibility to experimental autoimmune encephalitis (EAE), an animal model of MS, in female rodents [292]. Notably, in the EAE model, the same trigger (myelin basic protein) leads to decreased lymph node immune cells, decreased reactive cells, and decreased cytokines, as well as increased spleen-derived "anti-inflammatory" cytokines in males $[292,293]$. The same stimulus, then, produces both different immune responses and different delivery of immune signals to the brain. Despite the female predominance of EAE, E2 improves EAE severity in both males and females [294]. Indeed, while multiple studies support the immunomodulatory effect of E2, suggesting its suppression of the microglial "inflammatory" state and dosedependent suppression of the synthesis of a range of cytokines (TNF-a, IL-1B, MCP2) [295], the role of E2 in the regulation of immune response is complex and likely both cell- and contextdependent [294]. Sex steroids are key regulators of immune cell phenotype and function, with demonstrated roles in the regulation of both adaptive and innate immunity. Androgens and estrogens have been shown to regulate immune cell proliferation, differentiation, and apoptosis, as well as cytokine and immunoglobulin production [296-298]. Of note, sex steroids are synthesized de novo in the brain (neurons, glia), and hence their immunomodulatory effects can occur locally, representing paracrine and autocrine rather than classically endocrine effects (reviewed in ref. [299].

Stress axis. The importance of antecedent stress, stress sensitivity, and stress axis dysregulation in affective illness is, at this point, axiomatic. Stress in relation to affective disorders can be viewed from three distinct perspectives-stress as an environmental stimulus, the stress axis as an outcome measure, and the stress axis as a mediator of change in physiology (e.g., neural network or immune function) or behavior. Sex differences in stress are reviewed elsewhere [300-302], but several deserve mention in relation to affective disorder. First, as noted above, sex may elicit different responses from the environment (i.e., women are subject to different, potentially stressful interactions because of their sex). Second, women are twice as likely to experience stress-related disorders (MDD, anxiety, PTSD, obesity (also eating disorders and most phobias)) and more likely to develop them after trauma, physical abuse, or maternal distress during infancy [303-308]. Prenatal stress results in earlier behavioral problems in boys, with girls showing stronger effects (and increased amygdalar volumes) later [309, 310]. Third, the hypothalamic-pituitary-adrenal (HPA) axis may respond differently as a function of sex and is regulated by reproductive steroids. Sex differences in measures of HPA axis activity take the form of differences in magnitude, effects in one sex but not the other, and opposite effects. For example, men have greater stimulation of adrenocorticotropic hormone (ACTH) and cortisol compared with women after the Trier Social Stress Test (TSST) [311], and both CRH- and exercise-stimulated ACTH and cortisol are greater in men than women even in the absence of differences in reproductive steroids (i.e., under $\mathrm{GnRH}$-induced hypogonadism [312], although also see ref. [302]). Early trauma is positively associated with basal ACTH in women and negatively associated in men, while severe trauma is associated positively with ACTH response to $\mathrm{CRH}$ in men, but not women [313]. Of note, this literature is filled with ostensible inconsistencies, no doubt a function of the nature, duration, and timing (developmentally) of the stressors as well as the measures obtained.

Not surprisingly, sex differences have been reported in many components of the stress response, including differences in elicited changes in brain structure, non-HPA physiologic response (e.g., immune response noted above), and behavior. Chronic stress causes atrophy of dendrites in medial prefrontal cortex and hippocampus (CA3 pyramidal cells) only in male rodents [314, 315], whereas projections from medial prefrontal cortex to amygdala show (estrogen-dependent) increased spine density and dendritic expansion after chronic stress only in females [316]. These data are complemented by behavioral studies demonstrating that stressors like tail pinch increase associative learning (e.g., classically conditioned eyeblink response) in male rodents and produce learning deficits in females [317, 318]. Further, stress effects on learning are mediated by different brain regions and circuits in males and females (i.e., the mPFC, particularly in its connection to the amygdala, is critical to disrupted learning in females but not to enhanced learning in males, which involves activation of the BNST (not seen in females)) [319]. It should be noted that the sex differences in learning after acute stress are reversed for chronic stress, in which memory deficits are observed in males, but not females [236, 320]. As described above, the same repeated stress paradigm producing similar deficits in genetically identical male and female mice yields amazingly distinct, sexdependent profiles of differentially expressed genes (about 20\% overlap) compared with unstressed control animals [264]. Further, subchronic variable stress induces multiple depression-associated behavioral deficits (e.g., decreased sucrose preference, latency to eat in a novel environment) in female but not male mice, with, again, sex-dependent difference in the transcriptional response to stress in the nucleus accumbens [321]. A variety of findings converge in suggesting that women differentially process stressful stimuli: negative, arousing stimuli evoke faster and greater EEG responses in women [322], and emotion-evoking tasks produce greater activation of the locus coeruleus in women than men [323]. In parallel, the dendritic structure and post CRF receptor signaling in the locus coeruleus in rodents favor an exaggerated response to stress in females [324].

Effects of gonadal steroids. Many of the myriad sex differences in stress processing are attributable to differential exposure to reproductive steroids, which, with their metabolites, play a major role in modulation of the stress response. The CRF receptor has an ERE [325], and many components of the HPA axis vary across the estrus or menstrual cycle. Basal and stimulated ACTH and cortisol levels are higher in female rodents and during proestrus (when E2 and progesterone levels are high) [326-328]. These sex differences are eliminated by ovariectomy, as are many of the sex differences 
in brain region-specific structural and functional effects of stress noted above (e.g., the expansion of dendrites and spines in the mPFC-amygdala projections in females [316] or the sex-divergent effects of acute stress on classical eyeblink conditioning [319]). Of note, metabolites of reproductive steroids also regulate the response to stress. Thus, metabolites of progesterone (allopregnanolone) and testosterone (dihydrotestosterone) both dampen the response to stress in rodents, the former through acute effects on the GABA receptor and the latter through ER- $\beta$ $[329,330]$.

\section{HOW MIGHT SEX CONTRIBUTE TO DIFFERENTIAL CAPACITY FOR AFFECTIVE REGULATION?}

Affect regulation is dynamic. The ability to change and regulate affective state (whether externally or internally facilitated) appears at an early age, and while this capability may be "programmed" by genomic or early environmental events (contributing to "disposition"), it is also modified as a function of experience and environment throughout life. This view is consistent with the following: (1) the known "cumulative" effects of stressors (leading to different genomic expression patterns in response to subsequent stress [331] and greater susceptibility to affective disturbance); (2) other environmental (e.g., hormonal or experiences with mastery and control) and genomic contributions to susceptibility and resilience; and (3) the plasticity of affective regulation that allows for both increased susceptibility to affective disturbance and development of capacities/strategies for decreasing affective dysregulation.

Sex differences in affective disorder-particularly the presence of sex-specific, reproductive-related mood disorders in women (postpartum depression (PPD), premenstrual dysphoric disorder (PMDD), and perimenopausal depression)—provide unparalleled insights into this dynamic process of affective regulation. Employing hormone manipulation paradigms involving blinded reproductive steroid administration, often in the context of $\mathrm{GnRH}$ induced ovarian suppression, we have been able to demonstrate a clear role for ovarian steroids in both PMDD and PPD [332, 333]. Thus, despite normal reproductive endocrine function, the depressed state in these disorders is triggered by levels or changes in ovarian steroids that are without impact on affect in women lacking a history of PMDD or PPD. These affective disorders, then, represent the combination of a regulatory role for ovarian steroids on affective state with a susceptibility that permits normal reproductive endocrine signals to precipitate a dysphoric affective state. Put differently, women with these affective disorders are differentially susceptible to reproductive steroids such that a normal signal produces an abnormal behavioral state. How might this process-as well as its absence in men-be understood?

Cortical/genetic networks in males and females function

differently or are differentially responsive to stimuli like stress that load on development of affective dysregulation

Differential processing of affective-relevant stimuli

Consistent with the animal studies noted above, the same stimulus may be processed differently in men and women. Supporting examples (also described above) include the following: (1) Sex differences have been described in cortical networks relevant for affect; and (2) stress activates the brain differently in males and females. Stress leads to activation changes in the PFC (increased) and in the OFC (decreased) of males, whereas females show activation of limbic structures [334]. Further, different neural strategies are employed to cognitively control emotions (e.g., cognitive control decreases amygdalar activity in males but increases activity in the ventral striatum, ACC, and frontal regions in females) $[335,336]$. Thus, networks may be differentially elicited or differentially deployed in response to affective stimuli.
Women process affective-related/social stimuli differently Women experience emotional stimuli as more arousing than men and experience increased free recall, particularly for personal life events as well as increased memory for emotional events [337]. Affective valence category-specific sex differences in emotional appraisal have also been described [338]. Women have greater sensitivity to others, increased self-awareness, and increased capacity to manage new situations [339]. Women ruminate more than men [279], which may load on susceptibility to depression. As with the "orchid/dandelion dichotomy" [340, 341], whereby the environmentally sensitive child will do worse under environmentally stressful and better under nurturing conditions than the environmentally insensitive child, so the "increased sensitivity" of women to socio-affective stimuli may allow for greater emotional flexibility (under good conditions) but greater stress-related adverse consequences under unfavorable conditions. Sex differences in social and other risk factors for experiencing depression have been described by Kendler and Gardner [342]: failures in interpersonal relationships (marital dissatisfaction, interpersonal loss, loss of social support) play a stronger etiologic role in depression for women, while stressful life events in the past year, history of childhood sexual abuse, failure to achieve expected goals, and lowered self-worth are more prevalent in male depression.

How might these different stressors acquire differing impact on susceptibility to affective dysregulation in men and women? Independent of cultural expectations that impact the emotional salience of events, reproductive steroids influence network development and regulation such that environmental events are differentially processed. This is true at an organizational level as well, where E2 or testosterone will shape both circuit development AND subsequent sensitivity to (hormonal) stimuli [74-76]. Differential processing can be seen at the level of both neural and gene networks. As described above, Ingalhalikar et al. [204] demonstrated that the connectivity patterns in the brains of women may result in different processing of information, favoring better integration of between-hemisphere, analytical, and intuitive modes. Further (also described above), several studies demonstrated markedly different transcription profiles in men and women in association with major depression [264, 265]. These observations are consistent with those of Gaiteri et al. [343] that E2 modulates the synchrony of the gene interaction networks that are most disturbed in depression, suggesting a means by which pathological neural activity can be transformed (through E2 regulation of transcription and synaptic formation) into enduring cellular changes over time and across brain regions. So, the same genes are differentially organized and expressed within different cells and brain regions, with the differential expression under stressful circumstances potentially compromising cross-regional coordinated activity and adaptive behavioral strategies.

Changes in reproductive hormones may regulate affective state change

Several lines of evidence support this idea. (1) Teleologically, the reproductive hormonal regulation of sexual receptivity/motivation facilitates reproductive efficiency (sex during periods of optimal fertility). As such, behavioral sensitivity to hormone levels or changes is "hard-wired." (2) Changes in hormones have clear regulatory function. For example, the rate of change of blood cortisol concentration exerts a rapid (time-delayed) (5-30 min) feedback action on pituitary ACTH release [344], and fluctuating levels of the neurosteroid allopregnanolone induce altered function of GABA receptors through subunit-dependent conformational changes in the receptor [345]. (3) Changes in reproductive steroids modify the excitatory/inhibitory (E:I) balance that regulates behavioral state transitions and those between neural networks [346]. For example, postpartum E2 withdrawal impairs GABA-ergic inhibition and long-term depression in the basolateral 
amygdala (BLA) via downregulation of the GPR30 estrogen receptor (also called GPER) [347], and GPR30 activation decreases stress-induced anxiety by maintaining E:I balance in the BLA [348]. Similarly, allopregnanolone increases GABA-ergic interneuronal activity, and low progesterone concentrations are associated with increased amygdala activity in women [349]. Deficient inhibitory interneuronal function leads to a "tuning deficit" with decreased inhibitory filtering, increased "noise," disturbed behavioral state transitions, and both persistence of and failure to suppress the hyper-excitable DMN when the cognitive control network is activated [346]. (4) Changes in reproductive hormones in PMDD precipitate affective state change. Blind administration of either E2 or progesterone to women in whom PMDD-related affective disturbance had been eliminated by ovarian suppression resulted in precipitation of depression [332]. As it was unclear whether the precipitating event was a change (increase) in the hormone or the exceeding of a threshold level of hormone, a study was designed to administer reproductive steroids continuously for 3 months in association with ovarian suppression. Following the initial precipitation of depression in concert with hormone exposure, the affective state resolved and failed to reappear during the remaining 3 months of the stabilized hormone administration, thus demonstrating that the change in hormone (rather than the level achieved) was the inciting stimulus [350]. Similarly, prevention of the luteal phase-related increase in the progesterone metabolite allopregnanolone by the administration of dutasteride, a blocker of allopregnanolone synthesis, prevented the switch into the PMDD-related dysphoric state [351], thus mirroring the stresslike behavioral state observed following changes in allopregnanolone in rodents [345].

\section{Substrates of differential sensitivity}

The literature is replete with models (kindling, pharmacologic sensitization, time-dependent sensitization, learned helplessness) demonstrating that behavior and its underlying physiological substrates are highly context dependent. Genes and environment interact continuously, dynamically, and in a way that can enduringly change subsequent response to the same stimulus $[352,353]$. Sex, both endocrine and genetic, creates a context that shapes the nervous system and helps program subsequent responses (despite the considerable overlap between sexes that exists for most brain structures and functions). This capacity to create differential sensitivities is modeled in the interaction of genes and environment that results in susceptibility or resilience to stressful stimuli. Brain region-specific manipulation of the transcription of genes implicated in affective disorder and displaying sex-dependent regulation by stress (e.g., DNMT3a, Dusp-6) alters the sensitivity to stress and susceptibility to stressinduced, depression-like behaviors (increased with overexpression of the former and downregulation of the latter) [264, 321]. Even within members of a genetically similar inbred strain of mice, individual differences in stress sensitivity can be identified and, more remarkably, successfully conveyed to other mice with bone marrow transplantation [354]. These observations suggest that differences in behavioral sensitivity can occur through transcriptional responses to the environment that are enduring. Certainly, as noted above, some sex differences in sensitivity appear early and are sex chromosome (rather than sex hormone) dependent. In vitro studies of mouse embryos prior to sex differentiation (and hence sex hormone exposure) show that chromosomal sex drives different cellular responses to stressors and different transcriptional responses to exogenously administered sex hormones [355]. It is intuitively compelling, however, that differences in affective sensitivity reflect an ongoing and sculpting dialog between environment and genome, even if evidence of differential sensitivity exists at a cellular level. In support of this hypothesis is the observation by Dubey et al. [356] that lymphoblastoid cell lines from women with a reproductive endocrine-related mood disorder, PMDD, show, compared with controls, increased expression of a family of epigenetic modifying enzymes $(E S C / E(Z))$ as well as differential response to exogenous application of E2 and progesterone.

\section{CONCLUSIONS AND FUTURE DIRECTIONS}

We still know regrettably little about how affect is regulated. That said, for heuristic purposes, affective regulation can be parsed into the following: neural basis for affective experience (circuit formation/activation and synchronized firing), for changing circuit function (switching between states; cortical oscillation/dynamics), for dysregulation of circuit function (dysfunctional states and disturbed kinetics of state changes), and for susceptibility to sustained dysregulation of circuit function (genomic/transcriptional capacities for modulating interactions with the environment). On one hand, sex differences can be observed in these processes at almost any level of investigation, thus underscoring two critical points: (1) the failure to study both sexes will give us a false sense of understanding and deprive us of physiological insights; and (2) all physiology is context dependent, and sex, like developmental stage, age, past history, and genetic background, is a context (and a particularly powerful one as we have described). On the other hand, we simply do not understand the meaning and relevance of many of the sex differences that we have detailed above or that have been described elsewhere. Despite the multitude of studies documenting sex differences in the brains of lower animals, with the exception of the hypothalamus (in which cyclic pulsatile gonadotropin secretion is present in women but not men) most sex differences in the human brain have relatively modest effect sizes, with considerable overlap between sexes.

Studies of sex differences in human affective regulation are largely characterized by their inconsistencies, which might lead one to conclude that these differences are neither meaningful nor actionable. It is important, however, to bear in mind that human studies, particularly those of the brain, entail multiple methodologic complexities. (1) It is immensely more difficult to control for potential confounds-particularly in studies of brain and behavior -in humans than animals. (2) The expense of human studies often precludes the recruiting of sample sizes sufficiently powered to detect interaction effects between sex and the specific outcome measures. (3) Intra-sex variability often exceeds between-sex variability (which does not mean that relevant sex differences are absent or inconsequential). (4) The methodologic factors responsible for many of the current inconsistencies are legion and include diagnostic methods, sample age, statistical methods, reproductive state (prepubertal, premenstrual, postmenopausal), and menstrual cycle phase. This is particularly true when examining imaging studies, in which the following variables are seen: brain region (region of interest), volumetric measurement strategy, imaging method (PET vs. structural MRI vs. functional MRI), nature of imaging analysis (e.g., activation vs. connectivity), and nature of stimulus (e.g., cognitive vs. affective), to name just a few. Systematic efforts to employ common, validated methods and rigorous study designs in adequately powered studies will greatly improve our ability to detect and interpret meaningful sex differences in affective regulation.

Although a picture is emerging in which affective disorders may represent a "convergent" process (i.e., different physiologic routes to the same behavioral phenotype), we nonetheless must avoid the temptation to prematurely ascribe etiopathogenic meaning to cross-sectional snapshots of observed differences. Rather, we should attempt to develop common methodologies for examining the substrates of affective regulation, leverage big data, and thereby enable sex differences to help illuminate the neural antecedents of behavior, detect novel sources of variance, and pressure test our assumptions about pathophysiology. 


\section{ACKNOWLEDGEMENTS}

This work was written as part of Peter J. Schmidt's official duties as a Government employee. The views expressed in this article do not necessarily represent the views of the NIMH, NIH, HHS, or the US Government. This research was supported by the Intramural Research Program of the NIMH, NIH (NIMH Project \# MH002865).

\section{ADDITIONAL INFORMATION}

Competing interests: The authors declare no competing interests.

Publisher's note: Springer Nature remains neutral with regard to jurisdictional claims in published maps and institutional affiliations.

\section{REFERENCES}

1. McCarthy MM, Konkle ATM. When is a sex difference not a sex difference? Front Neuroendocrinol. 2005;26:85-102.

2. Patsopoulos NA, Tatsioni A, loannidis JP. Claims of sex differences: an empirical assessment in genetic associations. JAMA. 2007;298:880-93.

3. Kessler RC, Berglund P, Demler O, Jin R, Merikangas KR, Walters EE. Lifetime prevalence and age-of-onset distributions of DSM-IV disorders in the national comorbidity survey replication. Arch Gen Psychiatry. 2005;62:593-602.

4. Kessler RC, McGonagle KA, Swartz M, Blazer DG, Nelson CB. Sex and depression in the National Comorbidity Survey I: lifetime prevalence, chronicity and recurrence. J Affect Disord. 1993;29:85-96.

5. Weissman MM, Bland R, Joyce PR, Newman S, Wells JE, Witchen HU. Sex differences in rates of depression: cross-national perspectives. J Affect Disord. 1993;29:77-84.

6. Weissman MM, Klerman GL. Sex differences in the epidemiology of depression. Arch Gen Psychiatry. 1977;34:98-111.

7. Leibenluft $E$, Hardin TA, Rosenthal NE. Gender differences in seasonal affective disorder. Depression. 1995;3:13-19.

8. Maeng LY, Milad MR. Sex differences in anxiety disorders: interactions between fear, stress, and gonadal hormones. Horm Behav. 2015;76:106-17.

9. Yonkers KA, Bruce SE, Dyck IR, Keller MB. Chronicity, relapse, and illness-course of panic disorder, social phobia, and generalized anxiety disorder: findings in men and women from 8 years of follow-up. Depress Anxiety. 2003;17:173-9.

10. Altemus M, Sarvaiya N, Neill EC. Sex differences in anxiety and depression clinical perspectives. Front Neuroendocrinol. 2014;35:320-30.

11. Weissman MM, Klerman GL. Gender and depression. Trends Neurosci. 1985;8:416-20.

12. Leibenluft E. Women with bipolar illness: clinical and research issues. Am J Psychiatry. 1996;153:163-73.

13. Altshuler LL, Post RM, Leverich GS, Mikalauskas K, Rosoff A, Ackerman L. Antidepressant-induced mania and cycle acceleration: a controversy revisited. Am J Psychiatry. 1995;152:1130-8.

14. Angold A, Costello EJ. Puberty and depression. Child Adolesc Psychiatr Clin N Am. 2006;15:919-37.

15. Kessler RC. Epidemiology of women and depression. J Affect Disord. 2003;74:5-13.

16. McGee R, Feehan M, Williams S, Anderson J. DSM-III disorders from age 11 to age 15 years. J Am Acad Child Adolesc Psychiatry. 1992;31:51-59.

17. Patton GC, Hibbert ME, Carlin J, Shao Q, Rosier M, Caust J et al. Menarche and the onset of depression and anxiety in Victoria, Australia. J Epidemiol Community Health. 1996;50:661-6.

18. Wade TJ, Cairney J, Pevalin DJ. Emergence of gender differences in depression during adolescence: national panel results from three countries. J Am Acad Child Adolesc Psychiatry. 2002;41:190-8.

19. Cohen P, Cohen J, Kasen S, Velez CN, Hartmark C, Johnson J et al. An epidemiological study of disorders in late childhood and adolescence-l. Age- and gender-specific prevalence. J Child Psychol Psychiatry. 1993;34:851-67.

20. Anderson JC, Williams S, McGee R, Silva PA. DSM-III disorders in preadolescent children: prevalence in a large sample from the general population. Arch Gen Psychiatry. 1987;44:69-77.

21. Leibenluft E. Gender differences in major depressive disorder and bipolar disorder. CNS Spectr. 1999:4:25-33.

22. Costello EJ, Worthman C, Erkanli A, Angold A. Prediction from low birth weight to female adolescent depression: a test of competing hypotheses. Arch Gen Psychiatry. 2007;64:338-44.

23. Thase ME, Reynolds CF, Frank E, Simons AD, McGeary J, Fasiczka AL et al. Do depressed men and women respond similarly to cognitive-behavior therapy. Am J Psychiatry. 1994;151:500-5.

24. Winokur G, Tsuang MT, Crowe RR. The lowa 500: affective disorder in relatives of manic and depressed patients. Am J Psychiatry. 1982;139:209-12.
25. Burke KC, Burke JD, Regier DA, Rae DS. Age at onset of selected mentaldisorders in five community populations. Arch Gen Psychiatry. 1990;47:511-8.

26. Frank E, Carpenter LL, Kupfer DJ. Sex differences in recurrent depression: are there any that are significant? Am J Psychiatry. 1988;145:41-45.

27. Kornstein SG, Schatzberg AF, Yonkers KA, Thase ME, Keitner Gl, Ryan CE et al. Gender differences in presentation of chronic major depression. Psychopharmacol Bull. 1995;31:711-8.

28. Nolen-Hoeksema S. Sex differences in unipolar depression: evidence and theory. Psychol Bull. 1987;101:259-82.

29. Spicer CC, Hare EH, Slater E. Neurotic and psychotic forms of depressive illness; evidence from age-incidence in a national sample. $\mathrm{Br} J$ Psychiatry. 1973;123:535-41.

30. Fava M, Abraham M, Alpert J, Nierenberg AA, Pava JA, Rosenbaum JF. Gender differences in Axis I comorbidity among depressed outpatients. J Affect Disord. 1996;38:129-33.

31. Kessler RC, McGonagle KA, Nelson CB, Hughes M, Swartz M, Blazer DG. Sex and depression in the National Comorbidity Survey Il: cohort effects. J Affect Disord. 1994;30:15-26.

32. Simpson HB, Nee JC, Endicott J. First-episode major depression. Few sex differences in course. Arch Gen Psychiatry. 1997;54:633-9.

33. Zlotnick C, Shea MT, Pilkonis PA, Elkin I, Ryan C. Gender, type of treatment, dysfunctional attitudes, social support, life events, and depressive symptoms over naturalistic follow-up. Am J Psychiatry. 1996;153:1021-7.

34. Keitner Gl, Ryan CE, Miller IW, Kohn R, Epstein NB. 12-month outcome of patients with major depression and comorbid psychiatric or medical illness (compound depression). Am J Psychiatry. 1991;148:345-50.

35. Srikant CB, Patel YC. Somatostatin receptors. Adv Exp Med Biol. 1985;188:291-304.

36. Van Loo HM, Aggen SH, Gardner CO, Kendler KS. Sex similarities and differences in risk factors for recurrence of major depression. Psychol Med. 2018;48:1685-93.

37. Winokur G, Coryell W, Keller M, Endicott J, Akiskal H. A prospective follow-up of patients with bipolar and primary unipolar affective-disorder. Arch Gen Psychiatry. 1993;50:457-65.

38. Curry J, Silva S, Rohde P, Ginsburg G, Kratochvil C, Simons A et al. Recovery and recurrence following treatment for adolescent major depression. Arch Gen Psychiatry. 2011;68:263-9.

39. Ernst C, Angst J. The Zurich Study. XII. Sex differences in depression. Evidence from longitudinal epidemiological data. Eur Arch Psychiatry Clin Neurosci. 1992;241:222-30.

40. Aneshensel CS. The natural history of depressive symptoms. Res Commun Ment Health. 1985;5:45-74.

41. Angst J, Dobler-Mikola A. Do the diagnostic criteria determine the sex ratio in depression? J Affect Disord. 1984;7:189-98.

42. Young MA, Fogg LF, Scheftner WA, Keller MB, Fawcett JA. Sex differences in the lifetime prevalence of depression: does varying the diagnostic criteria reduce the female/male ratio? J Affect Disord. 1990;18:187-92.

43. Karp JF, Frank E. Combination therapy and the depressed woman. Depression. 1995;3:91-98.

44. Bebbington PE, Brugha T, MacCarthy B, Potter J, Sturt E, Wykes T et al. The Camberwell Collaborative Depression Study, I: depressed probands - adversity and the form of depression. Br J Psychiatry. 1988;152:754-65.

45. Regier DA, Burke JD, Burke KC. Comorbidity of affective and anxiety disorders in the NIMH Epidemiologic Catchment Area Program. In: Maser JD, Cloninger CR, editors. Comorbidity of mood and anxiety disorders. Washington, DC: American Psychiatric Press; 1990. p. 113-22.

46. Blazer DG, Kessler RC, McGonagle KA, Swartz MS. The prevalence and distribution of major depression in a national community sample: the National Comorbidity Survey. Am J Psychiatry. 1994;151:979-86.

47. Reus VI. Behavioral aspects of thyroid disease in women. Psychiatr Clin North Am. 1989;12:153-65.

48. Whybrow PC. Sex differences in thyroid axis function: relevance to affective disorder and its treatment. Depression. 1995:3:33-42.

49. Moldin SO, Scheftner WA, Rice JP, Nelson E, Knesevich MA, Akiskal H. Association between major depressive disorder and physical illness. Psychol Med. 1993;23:755-61.

50. Doran AR, Rubinow DR, Roy A, Pickar D. CSF somatostatin and abnormal response to dexamethasone administration in schizophrenic and depressed patients. Arch Gen Psychiatry. 1986;43:365-9.

51. Glassman AH, Perel JM, Shostak M, Kantor SJ, Fleiss JL. Clinical implications of imipramine plasma levels for depressive illness. Arch Gen Psychiatry. 1977;34:197-204.

52. Old Age Depression Interest Group. How long should the elderly take antidepressants? A double-blind placebo-controlled study of continuation/prophylaxis therapy with dothiepin. Br J Psychiatry. 1993;162:175-82. 
53. Raskin A. Age-sex differences in response to antidepressant drugs. J Nerv Ment Dis. 1974;159:120-30

54. Coppen A, Whybrow PC, Noguera R, Maggs R, Prange AJ Jr. The comparative antidepressant value of L-tryptophan and imipramine with and without attempted potentiation by liothyronine. Arch Gen Psychiatry. 1972;26:234-41.

55. Kornstein SG, Schatzberg AF, Thase ME, Yonkers KA, McCullough JP, Keitner GI et al. Gender differences in treatment response to sertraline versus imipramine in chronic depression. Am J Psychiatry. 2000;157:1445-52.

56. Steiner M, Wheadon DE, Kreider MS. Antidepressant response to paroxetine by gender. Abstract No. NR462:176. Paper presented at the 146th annual meeting of the American Psychiatric Association, San Francisco. 1993.

57. Davidson J, Pelton S. Forms of atypical depression and their response to antidepressant drugs. Psychiatry Res. 1986;17:87-95.

58. Sramek JJ, Murphy MF, Cutler NR. Sex differences in the psychopharmacological treatment of depression. Dialogues Clin Neurosci. 2016;18:447-57.

59. Wohlfarth T, Storosum JG, Elferink AJ, van Zwieten BJ, Fouwels A, van den Brink W. Response to tricyclic antidepressants: independent of gender? Am J Psychiatry. 2004;161:370-2

60. Prange AJ Jr, Wilson IC, Rabin AM, Lipton MA. Enhancement of imipramine antidepressant activity by thyroid hormone. Am J Psychiatry. 1969;126:457-69.

61. Appelhof BC, Brouwer JP, van DR, Fliers E, Hoogendijk WJ, Huyser J et al. Triiodothyronine addition to paroxetine in the treatment of major depressive disorder. J Clin Endocrinol Metab. 2004;89:6271-6.

62. Papakostas GI, Cooper-Kazaz R, Appelhof BC, Posternak MA, Johnson DP, Klibanski $A$ et al. Simultaneous initiation (coinitiation) of pharmacotherapy with triiodothyronine and a selective serotonin reuptake inhibitor for major depressive disorder: a quantitative synthesis of double-blind studies. Int Clin Psychopharmacol. 2009;24:19-25.

63. Cooper-Kazaz R, Apter JT, Cohen R, Karagichev L, Muhammed-Moussa S, Grupper $\mathrm{D}$ et al. Combined treatment with sertraline and liothyronine in major depression: a randomized, double-blind, placebo-controlled trial. Arch Gen Psychiatry. 2007;64:679-88.

64. Garlow SJ, Dunlop BW, Ninan PT, Nemeroff CB. The combination of triiodothyronine (T3) and sertraline is not superior to sertraline monotherapy in the treatment of major depressive disorder. J Psychiatr Res. 2012;46:1406-13.

65. Greenblatt DJ, Friedman H, Burstein ES, Scavone JM, Blyden GT, Ochs HR et al. Trazodone kinetics: effect of age, gender, and obesity. Clin Pharmacol Ther. 1987;42:193-200

66. Moody JP, Tait AC, Todrick A. Plasma levels of imipramine and desmethylimipramine during therapy. Br J Psychiatry. 1967;113:183-93.

67. Preskorn SH, Mac DS. Plasma levels of amitriptyline: effect of age and sex. J Clin Psychiatry. 1985;46:276-7.

68. Warrington SJ. Clinical implications of the pharmacology of sertraline. Int Clin Psychopharmacol. 1991;6:11-21.

69. Yonkers KA, Kando JC, Cole JO, Blumenthal S. Gender differences in pharmacokinetics and pharmacodynamics of psychotropic medication. Am J Psychiatry. 1992;149:587-95.

70. Dawkins K, Potter WZ. Gender differences in pharmacokinetics and pharmacodynamics of psychotropics: focus on women. Psychopharmacol Bull. 1991;27:417-26.

71. Gex-Fabry M, Balant-Gorgia AE, Balant LP, Garrone G. Clomipramine metabolism: model-based analysis of variability factors from drug monitoring data. Clin Pharmacokinet. 1990;19:241-55.

72. Rubinow DR, Moore M. Sex-dependent modulation of treatment response. Dial Clin Neurosci. 2004;6:39-51.

73. Miller MA. Gender-based differences in the toxicity of pharmaceuticals-the Food and Drug Administration's perspective. Int J Toxicol. 2001;20:149-52.

74. Arnold AP. The effects of castration and androgen replacement on song, courtship, and aggression in zebra finches (Poephila guttata). J Exp Zool. 1975;191:309-26.

75. Phoenix $\mathrm{CH}$, Goy RW, Gerall AA, Young WC. Organizing action of prenatally administered testosterone propionate on the tissues mediating mating behavior in the female guinea pig. Endocrinology. 1959;65:369-82.

76. Barraclough CA, Gorski RA. Evidence that the hypothalamus is responsible for androgen-induced sterility in the female rat. Endocrinology. 1961;68:68-79.

77. Pfaff DW. Morphological changes in the brains of adult male rats after neonatal castration. J Endocrinol. 1966;36:415-6.

78. Raisman G, Field PM. Sexual dimorphism in the preoptic area of the rat. Science. 1971;173:731-3

79. Zehr JL, Todd BJ, Schulz KM, McCarthy MM, Sisk CL. Dendritic pruning of the medial amygdala during pubertal development of the male Syrian hamster. J Neurobiol. 2006;66:578-90.

80. Juntti SA, Tollkuhn J, Wu MV, Fraser EJ, Soderborg T, Tan S et al. The androgen receptor governs the execution, but not programming, of male sexual and territorial behaviors. Neuron. 2010;66:260-72.
81. Forger NG. Past, present and future of epigenetics in brain sexual differentiation. J Neuroendocrinol. 2018;30. https://doi.org/10.1111/jne.12492.

82. Murray EK, Hien A, De Vries GJ, Forger NG. Epigenetic control of sexual differentiation of the bed nucleus of the stria terminalis. Endocrinology. 2009;150:4241-7.

83. Nugent BM, Wright $C L$, Shetty AC, Hodes GE, Lenz KM, Mahurkar A et al. Brain feminization requires active repression of masculinization via DNA methylation. Nat Neurosci. 2015;18:690-7.

84. Lenz KM, Nugent BM, Haliyur R, McCarthy MM. Microglia are essential to masculinization of brain and behavior. J Neurosci. 2013;33:2761-72.

These studies demonstrate that immune cells in the brain interact with the nervous and endocrine systems during development and are crucial for sexual differentiation of brain and behavior.

85. Thornton JW. Evolution of vertebrate steroid receptors from an ancestral estrogen receptor by ligand exploitation and serial genome expansions. Proc Natl Acad Sci USA. 2001;98:5671-6.

86. Sellers K, Raval P, Srivastava DP. Molecular signature of rapid estrogen regulation of synaptic connectivity and cognition. Front Neuroendocrinol. 2015;36:72-89.

The authors review the actions of estradiol on neuronal function including the mechanisms by which estrogen receptors couple to intracellular signaling cascades, the ability of estrogen to rapidly modulate both neuronal function and structure in the hippocampus and the cortex, and the potential impact of estrogen on cognitive function in humans.

87. Yuen GS, McEwen BS, Akama KT. LIM kinase mediates estrogen action on the actin depolymerization factor Cofilin. Brain Res. 2011;1379:44-52.

88. Micevych PE, Mermelstein PG, Sinchak K. Estradiol membrane-initiated signaling in the brain mediates reproduction. Trends Neurosci. 2017;40:654-66.

89. Srivastava DP, Woolfrey KM, Jones KA, Shum CY, Lash LL, Swanson GT et al. Rapid enhancement of two-step wiring plasticity by estrogen and NMDA receptor activity. Proc Natl Acad Sci USA. 2008;105:14650-5.

In this study the authors observed that E2 rapidly alters neuronal "wiring" by increasing synaptic spines; however, the effects of estradiol on neuronal connections only become permanent if followed by activity-dependent depolarization.

90. Kelly MJ, Wagner EJ. Estrogen modulation of G-protein-coupled receptors. Trends Endocrinol Metab. 1999;10:369-74.

91. Majewska MD, Harrison NL, Schwartz RD, Barker JL, Paul SM. Steroid hormone metabolites are barbiturate-like modulators of the GABA receptor. Science. 1986;232:1004-7.

92. McEwen BS, Alves SE. Estrogen actions in the central nervous system. Endocr Rev. 1999;20:279-307.

93. Lai YJ, Yu D, Zhang JH, Chen GJ. Cooperation of genomic and rapid nongenomic actions of estrogens in synaptic plasticity. Mol Neurobiol. 2017;54:4113-26. $A$ review of the effects of estradiol by which both genomic and nongenomic mechanisms combine to endow estrogens with considerable diversity in the modulation of neural functions including synaptic plasticity.

94. Schwartz N, Verma A, Bivens CB, Schwartz Z, Boyan BD. Rapid steroid hormone actions via membrane receptors. Biochim Biophys Acta. 2016;1863:2289-98.

95. Sarkar SN, Huang RQ, Logan SM, Yi KD, Dillon GH, Simpkins JW. Estrogens directly potentiate neuronal L-type Ca2+ channels. Proc Natl Acad Sci USA. 2008;105:15148-53.

96. Zhang H, Xie M, Schools GP, Feustel PF, Wang W, Lei T et al. Tamoxifen mediated estrogen receptor activation protects against early impairment of hippocampal neuron excitability in an oxygen/glucose deprivation brain slice ischemia model. Brain Res. 2009;1247:196-211.

97. Zhang L, Sukhareva M, Barker JL, Maric D, Hao Y, Chang YH et al. Direct binding of estradiol enhances Slack (sequence like a calcium-activated potassium channel) channels' activity. Neuroscience. 2005;131:275-82.

98. Wu WW, Adelman JP, Maylie J. Ovarian hormone deficiency reduces intrinsic excitability and abolishes acute estrogen sensitivity in hippocampal CA1 pyramidal neurons. J Neurosci. 2011;31:2638-48.

99. Srivastava DP, Waters EM, Mermelstein PG, Kramar EA, Shors TJ, Liu F. Rapid estrogen signaling in the brain: implications for the fine-tuning of neuronal circuitry. J Neurosci. 2011;31:16056-63.

100. Wu TW, Wang JM, Chen S, Brinton RD. 17Beta-estradiol induced Ca2+ influx via L-type calcium channels activates the Src/ERK/cyclic-AMP response element binding protein signal pathway and BCL-2 expression in rat hippocampal neurons: a potential initiation mechanism for estrogen-induced neuroprotection. Neuroscience. 2005;135:59-72.

101. Cheong RY, Kwakowsky A, Barad Z, Porteous R, Herbison AE, Abraham IM. Estradiol acts directly and indirectly on multiple signaling pathways to phosphorylate CAMP-response element binding protein in GnRH neurons. Endocrinology. 2012;153:3792-803. 
102. Dominguez R, Liu R, Baudry M. 17-Beta-estradiol-mediated activation of extracellular-signal regulated kinase, phosphatidylinositol 3-kinase/protein kinase B-Akt and N-methyl-D-aspartate receptor phosphorylation in cortical synaptoneurosomes. J Neurochem. 2007;101:232-40.

103. Watters JJ, Campbell JS, Cunningham MJ, Krebs EG, Dorsa DM. Rapid membrane effects of steroids in neuroblastoma cells: effects of estrogen on mitogen activated protein kinase signalling cascade and c-fos immediate early gene transcription. Endocrinology. 1997;138:4030-3.

104. Zhang L, Li B, Zhao W, Chang YH, Ma W, Dragan M et al. Sex-related differences in MAPKs activation in rat astrocytes: effects of estrogen on cell death. Brain Res Mol Brain Res. 2002;103:1-11.

105. Hall JM, Couse JF, Korach KS. The multifaceted mechanisms of estradiol and estrogen receptor signaling. J Biol Chem. 2001;276:36869-72.

106. Hah N, Kraus WL. Hormone-regulated transcriptomes: lessons learned from estrogen signaling pathways in breast cancer cells. Mol Cell Endocrinol. 2014;382:652-64.

A review of the findings from next-generation sequencing methods that investigate estrogen-dependent transcriptional regulation, including the diversity of estrogens actions and the complex transcriptional dynamics in response to estrogen signaling.

107. Zhao Z, Fan L, Fortress AM, Boulware MI, Frick KM. Hippocampal histone acetylation regulates object recognition and the estradiol-induced enhancement of object recognition. J Neurosci. 2012;32:2344-51.

108. Zhao Z, Fan L, Frick KM. Epigenetic alterations regulate estradiol-induced enhancement of memory consolidation. Proc Natl Acad Sci USA. 2010;107:5605-10. The authors demonstrate that the beneficial effects of E2 on memory consolidation are associated with epigenetic alterations and mediated by dorsal hippocampal ERK signaling.

109. Fortress AM, Frick KM. Epigenetic regulation of estrogen-dependent memory. Front Neuroendocrinol. 2014;35:530-49.

110. Gogos A, Sbisa AM, Sun J, Gibbons A, Udawela M, Dean B. A role for estrogen in schizophrenia: clinical and preclinical findings. Int J Endocrinol. 2015;2015:615356.

111. Hammond R, Gibbs RB. GPR30 is positioned to mediate estrogen effects on basal forebrain cholinergic neurons and cognitive performance. Brain Res. 2011;1379:53-60.

112. Marrocco J, McEwen BS. Sex in the brain: hormones and sex differences. DialogClin Neurosci. 2016;18:373-83.

113. McEwen BS, Nasca C, Gray JD. Stress effects on neuronal structure: hippocampus, amygdala, and prefrontal cortex. Neuropsychopharmacology. 2016;41:3-23.

A comprehensive review of the effects of stress hormones on neural structures.

114. Bethea CL, Reddy AP, Tokuyama Y, Henderson JA, Lima FB. Protective actions of ovarian hormones in the serotonin system of macaques. Front Neuroendocrinol. 2009;30:212-38.

115. Bourque M, Dluzen DE, Di PT. Signaling pathways mediating the neuroprotective effects of sex steroids and SERMs in Parkinson's disease. Front Neuroendocrinol. 2012;33:169-78.

116. Pasqualini C, Leviel V, Guibert B, Faucon-Biguet N, Kerdelhue B. Inhibitory actions of acute estradiol treatment on the activity and quantity of tyrosine hydroxylase in the median eminence of ovariectomized rats. J Neuroendocrinol. 1991;3:575-80.

117. Blum M, McEwen BS, Roberts JL. Transcriptional analysis of tyrosine hydroxylase gene expression in the tuberoinfundibular dopaminergic neurons of the rat arcuate nucleus after estrogen treatment. J Biol Chem. 1987;262:817-21.

118. Bosse $\mathrm{R}, \mathrm{Di} P T$. Dopamine and GABAA receptor imbalance after ovariectomy in rats: model of menopause. J Psychiatry Neurosci. 1995;20:364-71.

119. Schiller $C E$, Johnson AL, Abate AC, Rubinow DR, Schmidt PJ. Reproductive steroid regulation of mood and behavior. Compr Physiol. 2016;6(3):1135-60.

120. Sun J, Walker AJ, Dean B, van den Buuse M, Gogos A. Progesterone: the neglected hormone in schizophrenia? A focus on progesterone-dopamine interactions. Psychoneuroendocrinology. 2016;74:126-40.

121. Becker JB. Gender differences in dopaminergic function in striatum and nucleus accumbens. Pharmacol Biochem Behav. 1999;64:803-12.

$A$ review of the effects of sex and sex hormones on dopaminergic function within the striatum and nucleus accumbens, as well as the mechanisms underlying the effects of estradiol on dopaminergic system function. The relevance of these findings to sex differences in patterns of psychostimulant use is also presented.

122. Becker JB. Sex differences in addiction. Dialogues Clin Neurosci. 2016;18:395-402.

123. Raymond V, Beaulieu M, Labrie F, Boissier J. Potent antidopaminergic activity of estradiol at the pituitary level on prolactin release. Science. 1978;200:1173-5.

124. Mermelstein PG. Membrane-localised oestrogen receptor alpha and beta influence neuronal activity through activation of metabotropic glutamate receptors. J Neuroendocrinol. 2009;21:257-62.
125. Rubinow DR, Schmidt PJ, Roca CA. Estrogen-serotonin interactions: implications for affective regulation. Biol Psychiatry. 1998;44:839-50.

126. Zhang L, Ma W, Barker JL, Rubinow DR. Sex differences in expression of serotonin receptors (subtypes $1 \mathrm{~A}$ and $2 \mathrm{~A}$ ) in rat brain: a possible role of testosterone. Neuroscience. 1999;94:251-9.

127. Park-Chung M, Malayev A, Purdy RH, Gibbs TT, Farb DH. Sulfated and unsulfated steroids modulate $\mathrm{g}$-aminobutyric acidA receptor function through distinct sites. Brain Res. 1999;830:72-87.

128. Nordstrom AL, Olsson $H$, Halldin C. A PET study of D2 dopamine receptor density at different phases of the menstrual cycle. Psychiatry Res. 1998;83:1-6.

129. Jovanovic H, Kocoska-Maras L, Radestad AF, Halldin C, Borg J, Hirschberg AL et al. Effects of estrogen and testosterone treatment on serotonin transporter binding in the brain of surgically postmenopausal women--a PET study. Neuroimage. 2015;106:47-54.

130. Frokjaer VG, Pinborg A, Holst KK, Overgaard A, Henningsson S, Heede $M$ et al Role of serotonin transporter changes in depressive responses to sex-steroid hormone manipulation: a positron emission tomography study. Biol Psychiatry. 2015;78:534-43.

131. Kugaya A, Epperson CN, Zoghbi S, van Dyck CH, Hou Y, Fujita M et al. Increase in prefrontal cortex serotonin $2 \mathrm{~A}$ receptors following estrogen treatment in postmenopausal women. Am J Psychiatry. 2003;160:1522-4.

132. Moses-Kolko EL, Price JC, Wisner KL, Hanusa BH, Meltzer CC, Berga SL et al Postpartum and depression status are associated with lower $[(11) \mathrm{C}]$ raclopride $\mathrm{BP}$ (ND) in reproductive-age women. Neuropsychopharmacology. 2012;37:1422-32.

133. Rekkas PV, Wilson AA, Lee VW, Yogalingam P, Sacher J, Rusjan P et al. Greater monoamine oxidase a binding in perimenopausal age as measured with carbon 11-labeled harmine positron emission tomography. JAMA Psychiatry. 2014;71:873-9.

134. Sacher J, Wilson AA, Houle S, Rusjan P, Hassan S, Bloomfield PM et al. Elevated brain monoamine oxidase $A$ binding in the early postpartum period. Arch Gen Psychiatry. 2010;67:468-74.

135. Shanmugan S, Loughead J, Cao W, Sammel MD, Satterthwaite TD, Ruparel K et al. Impact of tryptophan depletion on executive system function during menopause is moderated by childhood adversity. Neuropsychopharmacology. 2017:42:2398-406.

136. Berent-Spillson A, Persad CC, Love T, Tkaczyk A, Wang H, Reame NK et al. Early menopausal hormone use influences brain regions used for visual working memory. Menopause. 2010;17:692-9.

137. Berman KF, Schmidt PJ, Rubinow DR, Danaceau MA, Van Horn JD, Esposito G et al. Modulation of cognition-specific cortical activity by gonadal steroids: a positron-emission tomography study in women. Proc Natl Acad Sci USA. 1997;94:8836-41.

The first demonstration in women that physiologic levels of ovarian steroids modulate the activation of specific brain regions including the dorsolateral prefrontal cortex during working memory.

138. Macoveanu J, Henningsson S, Pinborg A, Jensen P, Knudsen GM, Frokjaer VG et al. Sex-steroid hormone manipulation reduces brain response to reward. Neuropsychopharmacology. 2016;41:1057-65.

139. Rupp HA, James TW, Ketterson ED, Sengelaub DR, Janssen E, Heiman JR. Neural activation in women in response to masculinized male faces: mediation by hormones and psychosexual factors. Evol Hum Behav. 2009;30:1-10.

140. Bayer J, Bandurski P, Sommer T. Differential modulation of activity related to the anticipation of monetary gains and losses across the menstrual cycle. Eur J Neurosci. 2013;38:3519-26.

141. Dreher J, Schmidt PJ, Kohn P, Furman D, Rubinow D, Berman KF. Menstrual cycle phase modulates reward-related neural function in women. Proc Natl Acad Sci USA. 2007;104:2465-70.

A neuroimaging study demonstrating in women that the activation of the reward network changes across the normal menstrual cycle.

142. Arelin K, Mueller K, Barth C, Rekkas PV, Kratzsch J, Burmann I et al. Progesterone mediates brain functional connectivity changes during the menstrual cycle-a pilot resting state MRI study. Front Neurosci. 2015;9:44.

143. Petersen N, Kilpatrick LA, Goharzad A, Cahill L. Oral contraceptive pill use and menstrual cycle phase are associated with altered resting state functional connectivity. Neuroimage. 2014;90:24-32

144. Syan SK, Minuzzi L, Costescu D, Smith M, Allega OR, Coote M et al. Influence of endogenous estradiol, progesterone, allopregnanolone, and dehydroepiandrosterone sulfate on brain resting state functional connectivity across the menstrual cycle. Fertil Steril. 2017;107:1246-55.

145. Hjelmervik H, Hausmann M, Osnes B, Westerhausen R, Specht K. Resting states are resting traits-an FMRI study of sex differences and menstrual cycle effects in resting state cognitive control networks. PLoS ONE. 2014;9:e103492.

146. DeBondt $T$, Meets $D$, Ullens $P$, Van, Hecke $W$, Acquemyn $Y$ et al. Stability of resting state networks in the female brain during hormonal changes and their relation to premenstrual symptoms. Brain Res. 2015;1624:275-85. 
147. Fisher PM, Larsen CB, Beliveau V, Henningsson S, Pinborg A, Holst KK et al. Pharmacologically induced sex hormone fluctuation effects on resting-state functional connectivity in a risk model for depression: a randomized trial. Neuropsychopharmacology. 2017;42:446-53.

148. Goldstein JM, Jerram M, Poldrack R, Ahern T, Kennedy DN, Seidman $L J$ et al. Hormonal cycle modulates arousal circuitry in women using functional magnetic resonance imaging. J Neurosci. 2005;25:9309-16.

149. Henningsson S, Madsen KH, Pinborg A, Heede M, Knudsen GM, Siebner HR et al. Role of emotional processing in depressive responses to sex-hormone manipulation: a pharmacological fMRI study. Transl Psychiatry. 2015;5:1-8.

150. Protopopescu X, Pan H, Altemus M, Tuescher O, Polanecsky M, McEwen B et al. Orbitofrontal cortex activity related to emotional processing changes across the menstrual cycle. Proc Natl Acad Sci USA. 2005;102:16060-5.

151. Shafir T, Love T, Berent-Spillson A, Persad CC, Wang H, Reame NK et al. Postmenopausal hormone use impact on emotion processing circuitry. Behav Brain Res. 2012;226:147-53.

152. Toffoletto S, Lanzenberger R, Gingnell M, Sundstrom-Poromaa I, Comasco E. Emotional and cognitive functional imaging of estrogen and progesterone effects in the female human brain: a systematic review. Psychoneuroendocrinology. 2014;50:28-52

153. Andreano JM, Cahill L. Menstrual cycle modulation of medial temporal activity evoked by negative emotion. Neuroimage. 2010;53:1286-93.

154. Joffe H, Deckersbach T, Lin NU, Makris N, Skaar TC, Rauch SL et al. Metabolic activity in the insular cortex and hypothalamus predicts hot flashes: an FDG-PET study. J Clin Endocrinol Metab. 2012;97:3207-15.

155. Engman J, Sundstrom Pl, Moby L, Wikstrom J, Fredrikson M, Gingnell M. Hormonal cycle and contraceptive effects on amygdala and salience resting-state networks in women with previous affective side effects on the pill. Neuropsychopharmacology. 2018;43:555-63.

156. Greicius MD, Flores BH, Menon V, Glover GH, Solvason HB, Kenna $H$ et al. Resting-state functional connectivity in major depression: abnormally increased contributions from subgenual cingulate cortex and thalamus. Biol Psychiatry. 2007:62:429-37.

157. Hamilton JP, Farmer M, Fogelman P, Gotlib IH. Depressive rumination, the default-mode network, and the dark matter of clinical neuroscience. Biol Psychiatry. 2015;78:224-30.

158. Kaiser RH, Andrews-Hanna JR, Wager TD, Pizzagalli DA. Large-scale network dysfunction in major depressive disorder: a meta-analysis of resting-state functional connectivity. JAMA Psychiatry. 2015;72:603-11.

159. Muller VI, Cieslik EC, Serbanescu I, Laird AR, Fox PT, Eickhoff SB. Altered brain activity in unipolar depression revisited: meta-analyses of neuroimaging studies. JAMA Psychiatry. 2017;74:47-55.

160. Sheline YI, Price JL, Yan Z, Mintun MA. Resting-state functional MRI in depression unmasks increased connectivity between networks via the dorsal nexus. Proc Natl Acad Sci USA. 2010;107:11020-5.

161. Williams LM. Precision psychiatry: a neural circuit taxonomy for depression and anxiety. Lancet Psychiatry. 2016;3:472-80.

162. Drysdale AT, Grosenick L, Downar J, Dunlop K, Mansouri F, Meng Y et al. Restingstate connectivity biomarkers define neurophysiological subtypes of depression. Nat Med. 2017:23:28-38.

163. De Vries GJ, Rissman EF, Simerly RB, Yang LY, Scordalakes EM, Auger CJ et al. A model system for study of sex chromosome effects on sexually dimorphic neural and behavioral traits. J Neurosci. 2002;22:9005-14.

164. Arnold AP. Mouse models for evaluating sex chromosome effects that cause sex differences in non-gonadal tissues. J Neuroendocrinol. 2009;21:377-86.

\section{A review of the landmark strategies developed by the author and his collea-} gues to investigate sex hormone-independent effects on brain organization.

165. Dewing P, Chiang CW, Sinchak K, Sim H, Fernagut PO, Kelly $S$ et al. Direct regulation of adult brain function by the male-specific factor SRY. Curr Biol. 2006;16:415-20.

166. Nguyen DK, Disteche CM. High expression of the mammalian X chromosome in brain. Brain Res. 2006;1126:46-49.

167. Reinius B, Jazin E. Prenatal sex differences in the human brain. Mol Psychiatry. 2009;14:987. 988-987, 989.

168. Skuse DH. X-linked genes and mental functioning. Hum Mol Genet. 2005;14: R27-R32. Spec No 1.

169. Bellott DW, Hughes JF, Skaletsky H, Brown LG, Pyntikova T, Cho TJ et al. Mammalian $Y$ chromosomes retain widely expressed dosage-sensitive regulators. Nature. 2014;508:494-9.

170. Balaton BP, Cotton AM, Brown CJ. Derivation of consensus inactivation status for X-linked genes from genome-wide studies. Biol Sex Differ. 2015;6:35.

171. Migeon BR. An overview of $X$ inactivation based on species differences. Semin Cell Dev Biol. 2016;56:111-6.

A review of the potential role of $X$ inactivation in a range of human disease conditions presented for a general medical readership.
172. Tukiainen T, Villani AC, Yen A, Rivas MA, Marshall JL, Satija R et al. Landscape of $X$ chromosome inactivation across human tissues. Nature. 2017;550:244-8.

173. Bonthuis PJ, Huang WC, Stacher Horndli CN, Ferris E, Cheng T, Gregg C. Noncanonical genomic imprinting effects in offspring. Cell Rep. 2015;12:979-91.

174. Deng X, Berletch JB, Nguyen DK, Disteche CM. X chromosome regulation: diverse patterns in development, tissues and disease. Nat Rev Genet. 2014;15:367-78.

175. Migeon BR. The role of $X$ inactivation and cellular mosaicism in women's health and sex-specific diseases. JAMA. 2006;295:1428-33.

176. Peeters SB, Yang C, Brown CJ. Have humans lost control: the elusive Xcontrolling element. Semin Cell Dev Biol. 2016;56:71-77.

177. Xu J, Deng X, Watkins R, Disteche CM. Sex-specific differences in expression of histone demethylases Utx and Uty in mouse brain and neurons. J Neurosci. 2008;28:4521-7.

178. Wang J, Syrett CM, Kramer MC, Basu A, Atchison ML, Anguera MC. Unusual maintenance of $X$ chromosome inactivation predisposes female lymphocytes for increased expression from the inactive X. Proc Natl Acad Sci USA. 2016;113: E2029-38.

179. Chess A. Monoallelic gene expression in mammals. Annu Rev Genet. 2016;50:317-27.

180. Jegu T, Aeby E, Lee JT. The $X$ chromosome in space. Nat Rev Genet. 2017;18:377-89.

181. Arnold AP, Reue K, Eghbali M, Vilain E, Chen X, Ghahramani N et al. The importance of having two X chromosomes. Philos Trans R Soc Lond B Biol Sci. 2016;371:20150113.

182. Silkaitis K, Lemos B. Sex-biased chromatin and regulatory cross-talk between sex chromosomes, autosomes, and mitochondria. Biol Sex Differ. 2014;5:2.

183. Reue K. Sex differences in obesity: $X$ chromosome dosage as a risk factor for increased food intake, adiposity and co-morbidities. Physiol Behav. 2017;176:174-82.

184. Chen X, McClusky R, Chen J, Beaven SW, Tontonoz P, Arnold AP et al. The number of $x$ chromosomes causes sex differences in adiposity in mice. PLoS Genet. 2012;8:e1002709.

185. Chen X, McClusky R, Itoh Y, Reue K, Arnold AP. X and Y chromosome complement influence adiposity and metabolism in mice. Endocrinology. 2013;154:1092-104.

186. Yang X, Schadt EE, Wang S, Wang H, Arnold AP, Ingram-Drake L et al. Tissuespecific expression and regulation of sexually dimorphic genes in mice. Genome Res. 2006;16:995-1004.

187. Tower J. Sex-specific gene expression and life span regulation. Trends Endocrinol Metab. 2017;28:735-47.

188. Nilsen J, Diaz Brinton R. Mitochondria as therapeutic targets of estrogen action in the central nervous system. Curr Drug Targets CNS Neurol Dis. 2004;3:297-313.

189. Simpkins JW, Yang SH, Sarkar SN, Pearce V. Estrogen actions on mitochondria-physiological and pathological implications. Mol Cell Endocrinol. 2008;290:51-59.

190. De Vries GJ, Forger NG. Sex differences in the brain: a whole body perspective. Biol Sex Differ. 2015;6:15.

191. Bonnin A, Goeden N, Chen K, Wilson ML, King J, Shih JC et al. A transient placental source of serotonin for the fetal forebrain. Nature. 2011:472:347-52.

192. Markle JG, Frank DN, Mortin-Toth S, Robertson CE, Feazel LM, Rolle-Kampczyk U et al. Sex differences in the gut microbiome drive hormone-dependent regulation of autoimmunity. Science. 2013;339:1084-8. These investigators were able to eliminate the 4-5-fold increased risk for diabetes in female NOD mice by transplantation of gut contents from an adult male to the young femalean effect mediated by the increased testosterone production from the transplanted microbiota.

193. Bayless DW, Shah NM. Genetic dissection of neural circuits underlying sexually dimorphic social behaviours. Philos Trans $\mathrm{R}$ Soc Lond B Biol Sci. 2016;371:20150109.

194. McCarthy M, De Vries G, Forger N. Sexual differentiation of the brain: a fresh look at mode, mechanisms, and meaning. In: Pfaff DW, Joels M (eds), Hormones, Brain, and Behavior 3rd ed., Vol 5. Oxford: Academic Press; pp. 3-32, 2017. A critical and comprehensive review of the evidence supporting possible mechanisms mediating sex differences in brain organization and function.

195. Murphy DG, DeCarli C, Daly E, Haxby JV, Allen G, White BJ et al. X-chromosome effects on female brain: a magnetic resonance imaging study of Turner's syndrome. Lancet. 1993;342:1197-1200.

196. Gur RC, Gur RE. Complementarity of sex differences in brain and behavior: from laterality to multimodal neuroimaging. J Neurosci Res. 2017;95:189-99. A comprehensive review of the evolution of findings from a range of brain imaging techniques supporting the presence of sex differences in both structural and functional connectivity in the human brain. 
197. Gur RC, Turetsky BI, Matsui M, Yan M, Bilker W, Hughett $P$ et al. Sex differences in brain gray and white matter in healthy young adults: correlations with cognitive performance. J Neurosci. 1999;19:4065-72.

198. Gur RC, Gunning-Dixon F, Bilker WB, Gur RE. Sex differences in temporo-limbic and frontal brain volumes of healthy adults. Cereb Cortex. 2002;12:998-1003.

199. Satterthwaite TD, Vandekar S, Wolf DH, Ruparel K, Roalf DR, Jackson C et al. Sex differences in the effect of puberty on hippocampal morphology. J Am Acad Child Adolesc Psychiatry. 2014;53:341-50.

200. Ruigrok AN, Salimi-Khorshidi G, Lai MC, Baron-Cohen S, Lombardo MV, Tait RJ et al. A meta-analysis of sex differences in human brain structure. Neurosci Biobehav Rev. 2014:39:34-50.

201. Alonso-Nanclares L, Gonzalez-Soriano J, Rodriguez JR, DeFelipe J. Gender differences in human cortical synaptic density. Proc Natl Acad Sci USA 2008; 105:14615-9.

202. Cowell PE, Turetsky BI, Gur RC, Grossman Rl, Shtasel DL, Gur RE. Sex differences in aging of the human frontal and temporal lobes. J Neurosci. 1994;14:4748-55.

203. Hausmann M. Why sex hormones matter for neuroscience: a very short review on sex, sex hormones, and functional brain asymmetries. J Neurosci Res. 2017;95:40-49.

204. Ingalhalikar M, Smith A, Parker D, Satterthwaite TD, Elliott MA, Ruparel K et al. Sex differences in the structural connectome of the human brain. Proc Natl Acad Sci USA. 2014;111:823-8.

The authors demonstrated that the connectivity patterns in the brains of women may result in different processing of information, favoring better integration of between-hemisphere, analytical, and intuitive modes.

205. Lenroot RK, Giedd JN. Sex differences in the adolescent brain. Brain Cogn. 2010;72:46-55.

206. Lenroot RK, Gogtay N, Greenstein DK, Wells EM, Wallace GL, Clasen LS et al. Sexual dimorphism of brain developmental trajectories during childhood and adolescence. Neurolmage. 2007;36:1065-73.

207. Neufang S, Specht K, Hausmann M, Gunturkun O, Herpertz-Dahlmann B, Fink GR et al. Sex differences and the impact of steroid hormones on the developing human brain. Cereb Cortex. 2009;19:464-73.

208. Peper JS, Brouwer RM, Schnack HG, van Baal GC, van Leeuwen M, van den Berg $\mathrm{SM}$ et al. Sex steroids and brain structure in pubertal boys and girls. Psychoneuroendocrinology. 2009;34:332-42.

209. Perrin JS, Herve P-Y, Leonard G, Perron M, Pike GB, Pitiot A et al. Growth of white matter in the adolescent brain: role of testosterone and androgen receptor. J Neurosci. 2008;28:9519-24.

210. Raznahan A, Lee $Y$, Stidd R, Long R, Greenstein D, Clasen L et al. Longitudinally mapping the influence of sex and androgen signaling on the dynamics of human cortical maturation in adolescence. Proc Natl Acad Sci USA. 2010;107:16988-93.

211. Glezerman M. Yes, there is a female and a male brain: morphology versus functionality. Proc Natl Acad Sci USA. 2016;113:E1971.

212. Joel D, Hanggi J, Pool J. Reply to Glezerman: Why differences between brains of females and brains of males do not "add up" to create two types of brains. Proc Natl Acad Sci USA. 2016;113:E1972.

213. Joel D, Persico A, Hanggi J, Pool J, Berman Z. Reply to Del Giudice et al., Chekroud et al., and Rosenblatt: Do brains of females and males belong to two distinct populations? Proc Natl Acad Sci USA. 2016;113:E1969-E1970.

214. Rosenblatt JD. Multivariate revisit to "sex beyond the genitalia". Proc Natl Acad Sci USA. 2016;113:E1966-E1967.

215. Chekroud AM, Ward EJ, Rosenberg MD, Holmes AJ. Patterns in the human brain mosaic discriminate males from females. Proc Natl Acad Sci USA. 2016;113: E1968.

216. Del Giudice M, Lippa RA, Puts DA, Bailey DH, Bailey JM, Schmitt DP. Joel et al.'s method systematically fails to detect large, consistent sex differences. Proc Natl Acad Sci USA. 2016;113:E1965.

217. Joel D, Berman Z, Tavor I, Wexler N, Gaber O, Stein Y et al. Sex beyond the genitalia: the human brain mosaic. Proc Natl Acad Sci USA. 2015;112:15468-73. A large MRI study demonstrating that although sex differences in brain and behavior are observed, the overlap in all brain regions between men and women is extensive, and the internal consistency within even a single brain is far less common than variability; i.e., individuals are mosaics.

218. Huang GZ, Woolley CS. Estradiol acutely suppresses inhibition in the hippocampus through a sex-specific endocannabinoid and mGluR-dependent mechanism. Neuron. 2012;74:801-8.

219. Tabatadze N, Huang G, May RM, Jain A, Woolley CS. Sex differences in molecular signaling at inhibitory synapses in the hippocampus. J Neurosci. 2015;35:11252-65

220. Boulware Ml, Weick JP, Becklund BR, Kuo SP, Groth RD, Mermelstein PG. Estradiol activates group I and II metabotropic glutamate receptor signaling, leading to opposing influences on CAMP response element-binding protein. J Neurosci. 2005;25:5066-78.
221. Meitzen J, Grove DD, Mermelstein PG. The organizational and aromatization hypotheses apply to rapid, nonclassical hormone action: neonatal masculinization eliminates rapid estradiol action in female hippocampal neurons. Endocrinology. 2012;153:4616-21.

222. Oberlander JG, Woolley CS. 17beta-Estradiol acutely potentiates glutamatergic synaptic transmission in the hippocampus through distinct mechanisms in males and females. J Neurosci. 2016;36:2677-90.

Using whole cell voltage clamp recordings in dorsal hippocampal tissue slices, the authors demonstrate that estradiol acutely potentiates glutamatergic synapses similarly in both sexes, but distinct ER subtypes mediate the presynaptic and postsynaptic aspects of potentiation in each sex. This provides an example of a latent sex difference in which different molecular mechanisms converge to the same functional endpoint in males and females.

223. Bangasser DA, Wiersielis KR, Khantsis S. Sex differences in the locus coeruleusnorepinephrine system and its regulation by stress. Brain Res. 2016;1641:177-88.

224. Valentino RJ, Bangasser DA. Sex-biased cellular signaling: molecular basis for sex differences in neuropsychiatric diseases. Dialog- Clin Neurosci. 2016;18:385-93. A review article focusing on CRF and the stress axis in which the authors discuss how the impact of sex on cell signaling and protein trafficking at the molecular level can create a differential vulnerability to a range of psychiatric illnesses.

225. Spencer-Segal JL, Waters EM, Bath KG, Chao MV, McEwen BS, Milner TA. Dis tribution of phosphorylated TrkB receptor in the mouse hippocampal formation depends on sex and estrous cycle stage. J Neurosci. 2011;31:6780-90.

226. Blume SR, Freedberg M, Vantrease JE, Chan R, Padival M, Record MJ et al. Sexand estrus-dependent differences in rat basolateral amygdala. J Neurosci. 2017;37:10567-86.

227. Hyde JS. Sex and cognition: gender and cognitive functions. Curr Opin Neurobiol. 2016:38:53-56.

228. Li R, Singh M. Sex differences in cognitive impairment and Alzheimer's disease. Front Neuroendocrinol. 2014;35:385-403.

229. Miller DI, Halpern DF. The new science of cognitive sex differences. Trends Cogn Sci. 2014;18:37-45.

230. Corsi-Cabrera M, Herrera P, Malvido M. Correlation between EEG and cognitive abilities: sex differences. Int J Neurosci. 1989;45:133-41.

231. Korgaonkar MS, Fornito A, Williams LM, Grieve SM. Abnormal structural networks characterize major depressive disorder: a connectome analysis. Biol Psychiatry. 2014;76:567-74.

232. Gong G, Rosa-Neto P, Carbonell F, Chen ZJ, He Y, Evans AC. Age- and genderrelated differences in the cortical anatomical network. J Neurosci. 2009;29:15684-93.

233. Tunc B, Solmaz B, Parker D, Satterthwaite TD, Elliott MA, Calkins ME et al. Establishing a link between sex-related differences in the structural connectome and behaviour. Philos Trans R Soc Lond B Biol Sci. 2016;371:20150111.

234. Satterthwaite TD, Wolf DH, Roalf DR, Ruparel K, Erus G, Vandekar S et al. Linked sex differences in cognition and functional connectivity in youth. Cereb Cortex. 2015;25:2383-94.

235. Nielsen JA, Zielinski BA, Ferguson MA, Lainhart JE, Anderson JS. An evaluation of the left-brain vs. right-brain hypothesis with resting state functional connectivity magnetic resonance imaging. PLoS ONE. 2013;8:e71275.

236. McEwen BS, Milner TA. Understanding the broad influence of sex hormones and sex differences in the brain. J Neurosci Res. 2017;95:24-39.

237. Hensch TK. Critical period regulation. Annu Rev Neurosci. 2004;27:549-79.

238. Sahay A, Hen R. Adult hippocampal neurogenesis in depression. Nat Neurosci. 2007;10:1110-5.

239. Dachtler J, Fox K. Do cortical plasticity mechanisms differ between males and females? J Neurosci Res. 2017;95:518-26.

240. Leranth C, Petnehazy O, MacLusky NJ. Gonadal hormones affect spine synaptic density in the CA1 hippocampal subfield of male rats. J Neurosci. 2003:23:1588-92.

241. Galea LA, McEwen BS, Tanapat $P$, Deak T, Spencer RL, Dhabhar FS. Sex differences in dendritic atrophy of CA3 pyramidal neurons in response to chronic restraint stress. Neuroscience. 1997;81:689-97.

242. Carrier N, Kabbaj M. Sex differences in the antidepressant-like effects of ketamine. Neuropharmacology. 2013;70:27-34.

243. Monteggia LM, Zarate C Jr. Antidepressant actions of ketamine: from molecular mechanisms to clinical practice. Curr Opin Neurobiol. 2015;30:139-43.

244. Sarkar A, Kabbaj M. Sex differences in effects of ketamine on behavior, spine density, and synaptic proteins in socially isolated rats. Biol Psychiatry. 2016;80:448-56.

245. Takahashi A, Chung JR, Zhang S, Zhang H, Grossman $\mathrm{Y}$, Aleyasin $\mathrm{H}$ et al Establishment of a repeated social defeat stress model in female mice. Sci Rep. 2017;7:12838. 
246. Trainor BC, Pride MC, Villalon LR, Knoblauch NW, Takahashi EY, Silva AL et al. Sex differences in social interaction behavior following social defeat stress in the monogamous California mouse (Peromyscus californicus). PLoS ONE. 2011;6: e17405.

247. Zanos P, Moaddel R, Morris PJ, Georgiou P, Fischell J, Elmer Gl et al. NMDAR inhibition-independent antidepressant actions of ketamine metabolites. Nature. 2016;533:481-6.

248. Niciu MJ, Luckenbaugh DA, lonescu DF, Guevara S, Machado-Vieira R. Clinical predictors of ketamine response in treatment-resistant major depression. J Clin Psychiatry. 2014;5:417-23.

249. Bath KG, Schilit A, Lee FS. Stress effects on BDNF expression: effects of age, sex, and form of stress. Neuroscience. 2013;239:149-56.

250. Lai IC, Hong CJ, Tsai SJ. Expression of CAMP response element-binding protein in major depression before and after antidepressant treatment. Neuropsychobiology. 2003;48:182-5.

251. Jang SW, Liu X, Chan CB, Weinshenker D, Hall RA, Xiao G et al. Amitriptyline is a TrkA and TrkB receptor agonist that promotes TrkA/TrkB heterodimerization and has potent neurotrophic activity. Chem Biol. 2009;16:644-56.

252. Dwivedi Y, Rizavi HS, Zhang H, Mondal AC, Roberts RC, Conley RR et al. Neurotrophin receptor activation and expression in human postmortem brain: effect of suicide. Biol Psychiatry. 2009;65:319-28.

253. Goodenough S, Schleusner D, Pietrzik C, Skutella T, Behl C. Glycogen synthase kinase 3beta links neuroprotection by 17beta-estradiol to key Alzheimer processes. Neuroscience. 2005;132:581-9.

254. Guennoun R, Labombarda F, Gonzalez Deniselle MC, Liere P, De Nicola AF, Schumacher $M$. Progesterone and allopregnanolone in the central nervous system: response to injury and implication for neuroprotection. J Steroid Biochem Mol Biol. 2015;146:48-61.

255. Nilsen J, Diaz Brinton R. Impact of progestins on estrogen-induced neuroprotection: synergy by progesterone and 19-norprogesterone and antagonism by medroxyprogesterone acetate. Endocrinology. 2002;143:205-12.

256. Schumacher M, Mattern C, Ghoumari A, Oudinet JP, Liere P, Labombarda F et al. Revisiting the roles of progesterone and allopregnanolone in the nervous system: resurgence of the progesterone receptors. Prog Neurobiol. 2014; 113:6-39.

257. Singh M, Su C. Progesterone and neuroprotection. Horm Behav. 2013;63:284-90.

258. Dubal DB, Wise PM. Estrogen and neuroprotection: from clinical observations to molecular mechanisms. Dialog- Clin Neurosci. 2002;4:149-61.

259. Zhang L, Rubinow DR, Xaing G, Li BS, Chang YH, Maric D et al. Estrogen protects against beta-amyloid-induced neurotoxicity in rat hippocampal neurons by activation of Akt. Neuroreport. 2001;12:1919-23.

260. Yao J, Chen S, Cadenas E, Brinton RD. Estrogen protection against mitochondrial toxin-induced cell death in hippocampal neurons: antagonism by progesterone. Brain Res. 2011;1379:2-10.

261. Zup SL, Madden AM. Gonadal hormone modulation of intracellular calcium as a mechanism of neuroprotection. Front Neuroendocrinol. 2016:42:40-52.

262. Garcia-Segura LM, Cardona-Gomez P, Naftolin F, Chowen JA. Estradiol upregulates Bcl-2 expression in adult brain neurons. NeuroReport. 1998;9:593-7.

263. Irwin RW, Yao J, To J, Hamilton RT, Cadenas E, Brinton RD. Selective oestrogen receptor modulators differentially potentiate brain mitochondrial function. J Neuroendocrinol. 2012:24:236-48.

264. Labonte B, Engmann O, Purushothaman I, Menard C, Wang J, Tan C et al. Sexspecific transcriptional signatures in human depression. Nat Med. 2017;23:1102-11.

A study of gene co-expression networks showing marked differences between men and women with MDD and controls. Little overlap was observed in the altered transcriptional network connectivity patterns in men and women with depression nor in male and female mice subjected to a chronic variable stress paradigm

265. Seney ML, Huo Z, Cahill K, French L, Puralewski R, Zhang J, et al. Opposite molecular signatures of depression in men and women. Biol Psychiatry. 2018;84:18-27.

266. Gray AL, Hyde TM, Deep-Soboslay A, Kleinman JE, Sodhi MS. Sex differences in glutamate receptor gene expression in major depression and suicide. Mol Psychiatry. 2015;20:1139.

267. Lim AS, Myers AJ, Yu L, Buchman AS, Duffy JF, De Jager PL et al. Sex difference in daily rhythms of clock gene expression in the aged human cerebral cortex. J Biol Rhythms. 2013;28:117-29.

268. Boivin DB, Shechter A, Boudreau P, Begum EA, Ng Ying-Kin NM. Diurnal and circadian variation of sleep and alertness in men vs. naturally cycling women. Proc Natl Acad Sci USA. 2016;113:10980-5.

269. Fischer D, Lombardi DA, Marucci-Wellman H, Roenneberg T. Chronotypes in the US - Influence of age and sex. PLoS ONE. 2017:12:e0178782.

270. Sheline YI, Barch DM, Donnelly JM, Ollinger JM, Snyder AZ, Mintun MA. Increased amygdala response to masked emotional faces in depressed subjects resolves with antidepressant treatment: an fMRI study. Biol Psychiatry. 2001;50:651-8.

271. Goldstein JM, Jerram M, Abbs B, Whitfield-Gabrieli S, Makris N. Sex differences in stress response circuitry activation dependent on female hormonal cycle. J Neurosci. 2010;30:431-8.

272. Wu Y, Li H, Zhou Y, Yu J, Zhang Y, Song M et al. Sex-specific neural circuits of emotion regulation in the centromedial amygdala. Sci Rep. 2016;6:23112.

273. Stevens JS, Hamann S. Sex differences in brain activation to emotional stimuli: a meta-analysis of neuroimaging studies. Neuropsychologia. 2012;50:1578-93.

274. Allen EA, Erhardt EB, Damaraju E, Gruner W, Segall JM, Silva RF et al. A baseline for the multivariate comparison of resting-state networks. Front Syst Neurosci. 2011;5:2.

275. Jung M, Mody M, Saito DN, Tomoda A, Okazawa H, Wada Y et al. Sex differences in the default mode network with regard to autism spectrum traits: a resting state fMRI study. PLoS ONE. 2015;10:e0143126.

276. Alarcon G, Cservenka A, Rudolph MD, Fair DA, Nagel BJ. Developmental sex differences in resting state functional connectivity of amygdala sub-regions. Neuroimage. 2015;115:235-44.

277. Mak LE, Minuzzi L, MacQueen G, Hall G, Kennedy SH, Milev R. The default mode network in healthy individuals: a systematic review and meta-analysis. Brain Connect. 2017;7:25-33.

278. Sheline Yl, Barch DM, Price JL, Rundle MM, Vaishnavi SN, Snyder AZ et al. The default mode network and self-referential processes in depression. Proc Natl Acad Sci USA. 2009;106:1942-7.

279. Shors TJ, Millon EM, Chang HY, Olson RL, Alderman BL. Do sex differences in rumination explain sex differences in depression? J Neurosci Res. 2017:95:711-8.

280. McHenry JA, Otis JM, Rossi MA, Robinson JE, Kosyk O, Miller NW et al. Hormonal gain control of a medial preoptic area social reward circuit. Nat Neurosci. 2017;20:449-58.

In this study the authors identify an estradiol regulated reward circuit in mice, suggesting the possible contribution of activational effects of sex steroids to reward dysfunction observed in depression.

281. Raison CL, Miller AH. The evolutionary significance of depression in Pathogen Host Defense (PATHOS-D). Mol Psychiatry. 2013;18:15-37.

282. Howren MB, Lamkin DM, Suls J. Associations of depression with C-reactive protein, IL-1, and IL-6: a meta-analysis. Psychosom Med. 2009;71:171-86.

283. Liu Y, Ho RC, Mak A. Interleukin (IL)-6, tumour necrosis factor alpha (TNF-alpha) and soluble interleukin-2 receptors (sIL-2R) are elevated in patients with major depressive disorder: a meta-analysis and meta-regression. J Affect Disord. 2012;139:230-9.

284. Lenz KM, McCarthy MM. A starring role for microglia in brain sex differences. Neuroscientist. 2015;21:306-21.

285. Tonelli LH, Holmes A, Postolache $\Pi$. Intranasal immune challenge induces sexdependent depressive-like behavior and cytokine expression in the brain. Neuropsychopharmacology. 2008;33:1038-48.

286. Wu TH, Lin CH. IL-6 mediated alterations on immobile behavior of rats in the forced swim test via ERK1/2 activation in specific brain regions. Behav Brain Res. 2008;193:183-91.

287. Moieni M, Irwin MR, Jevtic I, Olmstead R, Breen EC, Eisenberger NI. Sex differences in depressive and socioemotional responses to an inflammatory challenge: implications for sex differences in depression. Neuropsychopharmacology. 2015;40:1709-16

288. Eisenberger NI, Inagaki TK, Rameson LT, Mashal NM, Irwin MR. An fMRI study of cytokine-induced depressed mood and social pain: the role of sex differences. Neuroimage. 2009:47:881-90.

289. Bekhbat M, Neigh GN. Sex differences in the neuro-immune consequences of stress: focus on depression and anxiety. Brain Behav Immun. 2018;67:1-12.

290. Loram LC, Sholar PW, Taylor FR, Wiesler JL, Babb JA, Strand KA et al. Sex and estradiol influence glial pro-inflammatory responses to lipopolysaccharide in rats. Psychoneuroendocrinology. 2012;37:1688-99.

291. Whitacre CC. Sex differences in autoimmune disease. Nat Immunol. 2001:2:777-80.

292. Voskuhl RR, Pitchekian-Halabi H, MacKenzie-Graham A, McFarland HF, Raine CS. Gender differences in autoimmune demyelination in the mouse: implications for multiple sclerosis. Ann Neurol. 1996;39:724-33.

293. Kim S, Voskuhl RR. Decreased IL-12 production underlies the decreased ability of male lymph node cells to induce experimental autoimmune encephalomyelitis. J Immunol. 1999;162:5561-8.

294. Villa A, Vegeto E, Poletti A, Maggi A. Estrogens, neuroinflammation, and neurodegeneration. Endocr Rev. 2016;37:372-402.

295. Ishihara Y, Itoh K, Ishida A, Yamazaki T. Selective estrogen-receptor modulators suppress microglial activation and neuronal cell death via an estrogen receptordependent pathway. J Steroid Biochem Mol Biol. 2015;145:85-93.

296. Oertelt-Prigione $S$. The influence of sex and gender on the immune response. Autoimmun Rev. 2012;11:A479-A485. 
297. Trigunaite A, Dimo J, Jorgensen TN. Suppressive effects of androgens on the immune system. Cell Immunol. 2015;294:87-94.

298. Gilliver SC. Sex steroids as inflammatory regulators. J Steroid Biochem Mol Biol. 2010;120:105-15.

299. Rubinow KB. An intracrine view of sex steroids, immunity, and metabolic regulation. Mol. Metabol. 2018. https://doi.org/10.1016/j.molmet.2018.03.001.

This is a comprehensive review of the steroidogenic and steroid metabolizing capacity of immune cells, the regulation of immune cell steroidogenesis, and the biological effects of immune-derived sex steroids.

300. Bale TL, Epperson CN. Sex differences and stress across the lifespan. Nat Neurosci. 2015;18:1413-20.

A comprehensive review of sex-specific effects of stress across development in both animal model systems and humans.

301. Bangasser DA, Valentino RJ. Sex differences in stress-related psychiatric disorders: neurobiological perspectives. Front Neuroendocrinol. 2014;35:303-19.

302. Oyola MG, Handa RJ. Hypothalamic-pituitary-adrenal and hypothalamicpituitary-gonadal axes: sex differences in regulation of stress responsivity. Stress. 2017;20:476-94.

303. MacMillan HL, Fleming JE, Streiner DL, Lin E, Boyle MH, Jamieson E et al. Childhood abuse and lifetime psychopathology in a community sample. Am J Psychiatry. 2001;158:1878-83.

304. Baker A, Shalhoub-Kevorkian N. Effects of political and military traumas on children: the Palestinian case. Clin Psychol Rev. 1999;19:935-50.

305. Michopoulos V, Diaz MP, Wilson ME. Social change and access to a palatable diet produces differences in reward neurochemistry and appetite in female monkeys. Physiol Behav. 2016;162:102-11.

306. Nolen-Hoeksema S. Emotion regulation and psychopathology: the role of gender. Annu Rev Clin Psychol. 2012;8:161-87.

307. Pitzer M, Jennen-Steinmetz C, Esser G, Schmidt MH, Laucht M. Prediction of preadolescent depressive symptoms from child temperament, maternal distress, and gender: results of a prospective, longitudinal study. J Dev Behav Pediatr. 2011;32:18-26.

308. Tolin DF, Foa EB. Sex differences in trauma and posttraumatic stress disorder: a quantitative review of 25 years of research. Psychol Bull. 2006;132:959-92.

309. Buss C, Davis EP, Hobel CJ, Sandman CA. Maternal pregnancy-specific anxiety is associated with child executive function at 6-9 years age. Stress. 2011;14:665-76.

310. Buss C, Davis EP, Shahbaba B, Pruessner JC, Head K, Sandman CA. Maternal cortisol over the course of pregnancy and subsequent child amygdala and hippocampus volumes and affective problems. Proc Natl Acad Sci USA. 2012;109:E1312-9.

311. Stephens MA, Mahon PB, McCaul ME, Wand GS. Hypothalamic-pituitary-adrenal axis response to acute psychosocial stress: effects of biological sex and circulating sex hormones. Psychoneuroendocrinology. 2016;66:47-55.

312. Roca CA, Schmidt PJ, Deuster P, Danaceau MA, Altemus M, Putnam K et al. Sex-related differences in stimulated hypothalamic-pituitary-adrenal axis during induced gonadal suppression. J Clin Endocrinol Metab. 2005;90: 4224-31.

313. DeSantis SM, Baker NL, Back SE, Spratt E, Ciolino JD, Moran-Santa MM et al. Gender differences in the effect of early life trauma on hypothalamic-pituitaryadrenal axis functioning. Depress Anxiety. 2011;28:383-92.

314. McEwen BS, Morrison JH. The brain on stress: vulnerability and plasticity of the prefrontal cortex over the life course. Neuron. 2013;79:16-29.

315. Milner TA, Burstein SR, Marrone GF, Khalid S, Gonzalez AD, Williams TJ et al. Stress differentially alters mu opioid receptor density and trafficking in parvalbumin-containing interneurons in the female and male rat hippocampus. Synapse. 2013;67:757-72.

316. Shansky RM, Hamo C, Hof PR, Lou W, McEwen BS, Morrison JH. Estrogen promotes stress sensitivity in a prefrontal cortex-amygdala pathway. Cereb Cortex. 2010;20:2560-7.

317. Shors TJ, Chua C, Falduto J. Sex differences and opposite effects of stress on dendritic spine density in the male versus female hippocampus. J Neurosci. 2001;21:6292-7.

318. Wood GE, Shors TJ. Stress facilitates classical conditioning in males, but impairs classical conditioning in females through activational effects of ovarian hormones. Proc Natl Acad Sci USA. 1998;95:4066-71.

319. Maeng LY, Waddell J, Shors TJ. The prefrontal cortex communicates with the amygdala to impair learning after acute stress in females but not in males. J Neurosci. 2010;30:16188-96.

The authors investigated the mechanisms underlying the sex differences in the effects of stress on hippocampal learning in which acute stress exposure enhances classical eyeblink conditioning in male rats but impairs it in females. These data indicated that the MPFC is critically involved in females during stress to impair subsequent learning and does so via communication with the amygdala.
320. Bowman RE, Beck KD, Luine VN. Chronic stress effects on memory: sex differences in performance and monoaminergic activity. Horm Behav. 2003;43:48-59.

321. Hodes GE, Pfau ML, Purushothaman I, Ahn HF, Golden SA, Christoffel DJ et al. Sex differences in nucleus accumbens transcriptome profiles associated with susceptibility versus resilience to subchronic variable stress. J Neurosci. 2015;35:16362-76.

322. Kemp AH, Silberstein RB, Armstrong SM, Nathan PJ. Gender differences in the cortical electrophysiological processing of visual emotional stimuli. Neuroimage. 2004;21:632-46.

323. Filkowski MM, Olsen RM, Duda B, Wanger TJ, Sabatinelli D. Sex differences in emotional perception: meta analysis of divergent activation. Neuroimage. 2017;147:925-33.

324. Bangasser DA, Eck SR, Telenson AM, Salvatore M. Sex differences in stress regulation of arousal and cognition. Physiol Behav. 2018;187:42-50.

325. Vamvakopoulos NC, Chrousos GP. Evidence of direct estrogenic regulation of human corticotropin-releasing hormone gene expression. Potential implications for the sexual dimophism of the stress response and immune/inflammatory reaction. J Clin Invest. 1993;92:1896-902.

326. Handa RJ, Burgess LH, Kerr JE, O'Keefe JA. Gonadal steroid hormone receptors and sex differences in the hypothalamo-pituitary-adrenal axis. Horm Behav. 1994;28:464-76.

A seminal study that demonstrated the role of the non-aromatizable androgen DHT in mediating sex differences in HPA axis responsivity.

327. Rivier C. Female rats release more corticosterone than males in response to alcohol: influence of circulating sex steroids and possible consequences for blood alcohol levels. Alcohol Clin Exp Res. 1993;17:854-9.

328. Spinedi E, Salas M, Chisari A, Perone M, Carino M, Gaillard RC. Sex differences in the hypothalamo-pituitary-adrenal axis response to inflammatory and neuroendocrine stressors: evidence for a pituitary defect in the autoimmune disease-susceptible female Lewis rat. Neuroendocrinology. 1994;60:609-17.

329. Lund TD, Hinds LR, Handa RJ. The androgen 5a-dihydrotestosterone and its metabolite $5 \mathrm{a}$-androstan-3b,17b-diol inhibit the hypothalamo-pituitary-adrenal response to stress by acting through estrogen receptor b-expressing neurons in the hypothalamus. J Neurosci. 2006;26:1448-56.

Demonstration that the sex differences in HPA axis response to stress, specifically a decreased HPA axis in males, is mediated by a metabolite of the androgen DHT acting through estrogen receptor-beta.

330. Morrow AL, Devaud LL, Purdy RH, Paul SM. Neuroactive steroid modulators of the stress response. Ann N Y Acad Sci. 1995;771:257-72.

331. Gray JD, Rubin TG, Hunter RG, McEwen BS. Hippocampal gene expression changes underlying stress sensitization and recovery. Mol Psychiatry. 2014;19:1171-8.

332. Schmidt PJ, Nieman LK, Danaceau MA, Adams LF, Rubinow DR. Differential behavioral effects of gonadal steroids in women with and in those without premenstrual syndrome. N Engl J Med. 1998;338:209-16.

333. Bloch M, Schmidt PJ, Danaceau M, Murphy J, Nieman L, Rubinow DR. Effects of gonadal steroids in women with a history of postpartum depression. Am J Psychiatry. 2000;157:924-30.

334. Wang J, Korczykowski M, Rao H, Fan Y, Pluta J, Gur RC et al. Gender difference in neural response to psychological stress. Soc Cogn Affect Neurosci. 2007;2:227-39.

335. Kateri M, Kevin NO, Iris BM, John JDG, James JG. Gender differences in emotion regulation: an fMRI study of cognitive reappraisal. Group Process Inter Relat. 2008;11:143-62.

336. Kogler L, Gur RC, Derntl B. Sex differences in cognitive regulation of psychosocial achievement stress: brain and behavior. Hum Brain Mapp. 2015;36:1028-42.

337. Andreano JM, Cahill L. Sex influences on the neurobiology of learning and memory. Learn Mem. 2009;16:248-66.

338. Spalek K, Fastenrath M, Ackermann S, Auschra B, Coynel D, Frey J et al. Sexdependent dissociation between emotional appraisal and memory: a large-scale behavioral and fMRI study. J Neurosci. 2015;35:920-35.

339. Bekker MHJ, van Assen MALM. Autonomy-connectedness mediates sex differences in symptoms of psychopathology. PLoS ONE. 2017;12:e0181626.

340. Boyce WT. Differential susceptibility of the developing brain to contextual adversity and stress. Neuropsychopharmacology. 2016;41:142-62.

341. Boyce WT, Ellis BJ. Biological sensitivity to context: I. An evolutionarydevelopmental theory of the origins and functions of stress reactivity. Dev Psychopathol. 2005;17:271-301.

342. Kendler KS, Gardner CO. Sex differences in the pathways to major depression: a study of opposite-sex twin pairs. Am J Psychiatry. 2014;171:426-35. The authors examined risk factors for depression in opposite sex twin pairs.

343. Gaiteri C, Guilloux JP, Lewis DA, Sibille E. Altered gene synchrony suggests a combined hormone-mediated dysregulated state in major depression. PLoS ONE. 2010;5:e9970. 
344. Keenan DM, Licinio J, Veldhuis JD. A feedback-controlled ensemble model of the stress-responsive hypothalamo-pituitary-adrenal axis. Proc Natl Acad Sci USA. 2001;98:4028-33.

345. Shen $H$, Gong $Q H$, Aoki $C$, Yuan M, Ruderman $Y$, Dattilo $M$ et al. Reversal of neurosteroid effects at a4b2d GABAA receptors triggers anxiety at puberty. Nat Neurosci. 2007;10:469-77. Demonstration in mice that the timing and pattern of exposure to progesterone can significantly alter the conformation of the GABAA receptor complex to a configuration that induces anxiety-like behavior after re-exposure to progesterone. These effects are mediated by the neurosteroid metabolite of progesterone, allopregnanolone.

346. Krystal JH, Anticevic A, Yang GJ, Dragoi G, Driesen NR, Wang XJ et al. Impaired tuning of neural ensembles and the pathophysiology of schizophrenia: a translational and computational neuroscience perspective. Biol Psychiatry. 2017;81:874-85

347. Yang R, Zhang B, Chen T, Zhang S, Chen L. Postpartum estrogen withdrawal impairs GABAergic inhibition and LTD induction in basolateral amygdala complex via down-regulation of GPR30. Eur Neuropsychopharmacol. 2017; 27:759-72.

348. Tian Z, Wang Y, Zhang N, Guo YY, Feng B, Liu SB et al. Estrogen receptor GPR30 exerts anxiolytic effects by maintaining the balance between GABAergic and glutamatergic transmission in the basolateral amygdala of ovariectomized mice after stress. Psychoneuroendocrinology. 2013;38:2218-33.

349. Backstrom T, Bixo M, Johansson M, Nyberg S, Ossewaarde L, Ragagnin $G$ et al. Allopregnanolone and mood disorders. Prog Neurobiol. 2014;113:88-94.
350. Schmidt PJ, Martinez PE, Nieman LK, Koziol DE, Thompson KD, Schenkel L et al. Premenstrual dysphoric disorder symptoms following ovarian suppression: triggered by change in ovarian steroid levels but not continuous stable levels. Am J Psychiatry. 2017;174:980-9.

351. Martinez PE, Rubinow DR, Nieman LK, Koziol DE, Morrow AL, Schiller CE et al. 5alpha-Reductase inhibition prevents the luteal phase increase in plasma allopregnanolone levels and mitigates symptoms in women with premenstrual dysphoric disorder. Neuropsychopharmacology. 2016;4:1093-102.

352. Post RM, Rubinow DR, Ballenger JC. Conditioning and sensitisation in the longitudinal course of affective illness. Br J Psychiatry. 1986;149:191-201.

353. Weaver IC, Cervoni N, Champagne FA, D'Alessio AC, Sharma S, Seckl JR et al. Epigenetic programming by maternal behavior. Nat Neurosci. 2004;7:847-54.

354. Hodes GE, Pfau ML, Leboeuf M, Golden SA, Christoffel DJ, Bregman D et al. Individual differences in the peripheral immune system promote resilience versus susceptibility to social stress. Proc Natl Acad Sci USA. 2014;111:16136-41.

355. Penaloza C, Estevez B, Orlanski S, Sikorska M, Walker R, Smith C et al. Sex of the cell dictates its response: differential gene expression and sensitivity to cell death inducing stress in male and female cells. FASEB J. 2009;23:1869-79.

356. Dubey N, Hoffman JF, Schuebel K, Yuan Q, Martinez PE, Nieman LK et al. The $E S C / E(Z)$ complex, an effector of response to ovarian steroids, manifests an intrinsic difference in cells from women with premenstrual dysphoric disorder. Mol Psychiatry. 2017;8:1172-84. 